\title{
A Simple, Affordable, Rapid, Stabilized, Colorimetric, Versatile RT-LAMP assay to detect SARS-CoV-2
}

\author{
Juan García-Bernalt Diego \\ University of Salamanca https://orcid.org/0000-0001-6947-6806 \\ Pedro Fernández-Soto ( $\sim$ pfsoto@usal.es ) \\ Universidad de Salamanca https://orcid.org/0000-0002-4089-4307 \\ Marta Domínghez-Gil \\ Hospital Universitario Río Hortega \\ Moncef Belhassen-García \\ Complejo Asistencial Universitario de Salamanca \\ Juan Luis Muñoz Bellido \\ Complejo Asistencial Universitario de Salamanca \\ Antonio Muro \\ University of Salamanca https://orcid.org/0000-0003-0244-4740
}

\section{Article}

Keywords: Automated Testing Platforms, Dry Format, Room-temperature Storage

Posted Date: November 16th, 2020

DOI: https://doi.org/10.21203/rs.3.rs-103047/v1

License: (c) (i) This work is licensed under a Creative Commons Attribution 4.0 International License.

Read Full License 


\title{
Title
}

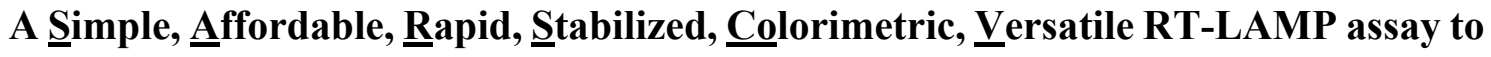 detect SARS-CoV-2}

\section{Authors list and affiliations}

Juan García-Bernalt Diego ${ }^{1}$, Pedro Fernández-Soto*1, Marta Domínguez-Gil ${ }^{2}$, Moncef Belhassen-García ${ }^{1,3}$, Juan Luis Muñoz Bellido ${ }^{4}$ and Antonio Muro ${ }^{1}$.

${ }^{1}$ Infectious and Tropical Diseases Research Group (e-INTRO), Biomedical Research Institute of Salamanca-Research Centre for Tropical Diseases at the University of Salamanca (IBSAL-CIETUS), Faculty of Pharmacy, University of Salamanca, Salamanca, Spain.

${ }^{2}$ Servicio de Microbiología, Hospital Universitario Río Hortega, Valladolid, Spain.

${ }^{3}$ Servicio de Medicina Interna, Sección de Enfermedades Infecciosas, Complejo Asistencia Universitario de Salamanca, University of Salamanca, Salamanca, Spain.

${ }^{4}$ Servicio de Microbiología y Parasitología, Complejo Asistencial Universitario de Salamanca, University of Salamanca, Salamanca, Spain.

\section{*Corrresponding autor}

Pedro Fernández-Soto, pfsoto@usal.es

\begin{abstract}
The SARS-Cov-2 pandemic has forced all countries worldwide to rapidly develop and implement widespread testing to control and manage the Coronavirus Disease 2019 (COVID-19). RT-qPCR is the gold standard molecular diagnostic method for COVID19 , mostly in automated testing platforms. These systems are accurate and effective, but also costly, time-consuming, high technological, infrastructure dependent and currently suffer from commercial reagent supply shortages. The reverse-transcription loopmediated isothermal amplification (RT-LAMP) can be used as alternative testing method. Here, we present a novel versatile (real-time and colorimetric) RT-LAMP for the simple (one-step) and rapid (as soon as $9 \mathrm{~min}$ ) detection of SARS-CoV-2 and demonstrate the assay on RT-qPCR-positive clinical samples. We further transformed the RT-LAMP into a dry format for room-temperature storage suitable for potentially ready-to-use COVID19 diagnosis. After further testing and validation, the Dry-RT-LAMP could be easily applied both in developed and in low-income countries yielding rapid and reliable results.
\end{abstract}




\section{INTRODUCTION}

Coronavirus disease 19 (COVID-19) is an infection caused by the novel coronavirus SARS-CoV-2, that emerged in China in December of 2019, becoming the seventh member of the Coronaviridae family to infect humans ${ }^{1}$. Although it is less severe than other previously described coronaviruses infecting humans, it has a significantly higher transmission capacity. This elevated transmission compelled the World Health Organization (WHO) to declare a global health emergency on January $31^{\text {st }} 2020$ and, subsequently, a pandemic situation on March $11^{\text {th }} 2020^{2}$. Until the date of writing this manuscript, the COVID-19 pandemic had already affected over 47 million people worldwide and caused over 1.2 million deaths (https://coronavirus.jhu.edu/map.html).

For COVID-19, a mean incubation period of 6.4 days (ranging from 2.1 to 11.1 days) is estimated $^{3}$. Clinical manifestations can range from mild flu-like symptoms to severe or critical, and patients can present an either symptomatic or asymptomatic infection. The later seem to account for 40 to $45 \%$ of cases $^{4}$. The most prevalent symptoms are fever, cough (either productive or not) and myalgia or fatigue, but other signs such as headache, hemoptysis and diarrhea may appear ${ }^{5,6}$. In severe presentations, COVID-19 is associated with pneumonia and acute respiratory distress syndrome (ARDS), for which elderly and chronic disease patients are particularly susceptible ${ }^{7}$. SARS-CoV-2 can also affect the gastrointestinal, nervous, or cardiovascular systems ${ }^{6}$. Timely diagnosis in the early infection stages is hindered by the aforementioned incubation period together with the asymptomatic course or unspecific manifestations of the illness in a high proportion of patients $^{5}$. Early diagnosis allows a prompt intervention, reducing the risk of developing more serious complications. Moreover, one of the main challenges to contain the spread of COVID-19 is the identification of asymptomatic cases.

In that sense, nucleic acid detection-based tests are reliable and accurate approaches for viral infection detection, being the RT-qPCR assay the main molecular method used for the detection of all kinds of coronaviruses, including SARS-Cov-2 ${ }^{8,9}$. Currently, COVID19 RT-qPCR-based tests, target mainly ORF1ab combined with genes coding for the E and N proteins of SARS-CoV-2 are available. However, protocols for commercial RTqPCR kits utilizes different reagents and different combination of the aforementioned genes depending on the country ${ }^{10}$. Besides, the devices to perform RT-qPCR result in a wide range of costs and processing times, as well as variations in tests accuracy ${ }^{11}$. Moreover, RT-qPCR technology is not easily adaptable for point-of-care diagnosis in 
low-resource settings due to the need for temperature cycling. An increasingly recognized alternative is loop-mediated isothermal amplification (LAMP) technology, a highly efficient, specific and rapid technology to amplify DNA at a constant temperature, using two or three primer sets and a Bst polymerase with high strand displacement activity ${ }^{12}$. Many prominent advantages of LAMP over PCR-based technologies in terms of sensitivity, specificity, rapidity, robustness, and cost have been extensively informed ${ }^{13}$. Additionally, different approaches have been developed to allow LAMP reagents storage, in a single tube at room temperature over extended periods, to be used for point-of-care testing $^{14}$. Reverse transcription LAMP (RT-LAMP) combines LAMP to amplify DNA from an RNA target in one-step reaction by directly adding a dedicated reverse transciptase ${ }^{10}$ or a DNA polymerase with reverse transcriptase activity to the reaction mixture. RT-LAMP shares the versatility and all the benefits of LAMP technology and has already been developed for the detection of numerous RNA viruses including virus influenza, Zika, Ebola, and MERS ${ }^{15}$. The prominent prospect of RT-LAMP in the context of COVID-19 diagnosis has been recently discussed by Augustine et al. ${ }^{16}$.

Thus, since the outbreak of COVID-19, in parallel with the emergence of new in-house and commercial RT-qPCR assays to detect SARS-CoV-2 RNA, numerous RT-LAMP assays have been rapidly developed mainly targeting ORF1ab ${ }^{17-24}$ and gene $\mathrm{N}^{17,19,22,25-30}$ sequences, which are the regions recommended for RT-qPCR by the Centre of Disease Control and Prevention (CDC, USA) ${ }^{31}$. Although less explored, some assays have also targeted Gen $\mathrm{S}^{17,19}$, Gen $\mathrm{E}^{30}$ and Gen $\mathrm{M}$ sequences ${ }^{32}$. A comparison of different RTLAMP for SARS-CoV-2 detection, including master mixes, primer sets, targeting genes, readout monitoring, and analytical sensitivity has been recently summarized and examined by Thompson $\&$ Lei $^{33}$. Those studies expose a wide variety of methodologies, sensitivities and results. Furthermore, a commercial technology based on RT-LAMP, ID NOW COVID-19 (Abbott Laboratories, USA) has been granted the Emergency Use Authorization (EUA) by the FDA ${ }^{9}$. RT-LAMP in combination with other molecular techniques such as CRISPR-Cas $12^{30}$ or recombinase polymerase assay (RPA) ${ }^{24}$, has also been optimized for SARS-CoV-2 detection. Additionally, various strategies to avoid RNA extraction and purification, one of the main bottlenecks molecular testing is facing now, have been presented, mainly for nasopharyngeal swabs ${ }^{24}$ and saliva ${ }^{34}$ analyses.

In this paper, with the aim of contributing to an effective COVID-19 diagnosis, we present a novel, specific, sensitive, rapid and versatile RT-LAMP assay for SARS-CoV-2 RNA detection. We demonstrate our RT-LAMP assay proper operation on clinical samples by 
using a portable real-time device and also in conventional colorimetric trials easily visualized to the naked eye. Furthermore, we report the development of a new simple one-step desiccation procedure to stabilize the RT-LAMP reagents in a single tube for potentially ready-to-use application in diagnosis of COVID-19. The Dry-RT-LAMP format could be very useful for easy testing in situations of high diagnostic demand and in low-resources settings.

\section{METHODS}

\section{Ethics statement}

The study protocol was approved by the Clinical Research Ethics Committee of Investigation with Drugs of the University Hospital of Salamanca, Spain (CEIMC 2020.06. 530). The procedures described here were carried out in accordance with the ethical standards described in the Revised Declaration of Helsinki in 2013. All patient data were anonymized and unidentified.

\section{Clinical specimens}

Nasopharyngeal swabs specimens were collected in Sample Preservation Solution (Mole Bioscience, SUNGO Europe B.V., Amsterdam, The Netherlands) as part of the routine testing of patients for COVID-19 at the University Hospital of Salamanca, Salamanca, Spain. Collected samples were delivered to the Laboratory of Microbiology, and then processed in a biosafety level 2 cabin until inactivation by mixing with a lysis buffer.

\section{RNA isolation and RT-qPCR amplification}

Samples were processed either by performing RNA isolation (NUCLISENS $^{\circledR}$ easyMAG ${ }^{\circledR}$, bioMérieux, France) and reverse transcription (RT) and amplification (VIASURE SARS-CoV-2 Real Time PCR Detection Kit, CerTest BIOTECH, Spain) separately, or in an integrated way in an automated platform (Cobas ${ }^{\circledR} 6800$, Roche, Switzerland) following manufactures' instructions. RT-qPCR for the detection of SARSCoV-2 RNA was performed using commercial kits and reagents targeting ORF1ab and gen N (VIASURE SARS-CoV-2) or ORF1ab and gen E (Cobas ${ }^{\circledR}$ SARS-CoV-2 Test) following manufacturers' instructions. Aliquots of purified RNA samples were stored at $-80^{\circ} \mathrm{C}$ until further analysis. For RNA samples analyzed, SARS-CoV-2 Cycle threshold 
(Ct) values for ORF1ab, E or $\mathrm{N}$ amplified targets were used as reference for the RTLAMP assays.

\section{Viral RNA positive control and patients' RNA samples selected}

A RNA isolate amplified by VIASURE SARS-CoV-2 Real Time PCR Detection Kit from a positive COVID-19 patient with a $\mathrm{Ct}=25 \mathrm{~min}$ for ORF1ab target and a $\mathrm{Ct}=29 \mathrm{~min}$ for gen $\mathrm{N}$ was selected as a well-established RNA-positive control to set up the COVIDLAMP assays (hereafter, $\mathrm{C}+$ ). The $\mathrm{Ct}$ values allowed us to determinate a concentration between $10^{5}$ and $10^{4}$ copies per RT-qPCR reaction (cpr) ( $5 \mu \mathrm{L}$ of sample), attending to the VIASURE SARS-CoV-2 Real Time PCR Detection Kit's handbook (https://www.certest.es/wp-content/uploads/2020/03/IU-NCO212enes0420-rev.01.pdf). Therefore, a concentration of $2 \times 10^{4} \mathrm{cpr}(1 \mu \mathrm{L}$ of $\mathrm{C}+)$ was estimated for analytical sensitivity calculations.

To further test COVID-LAMP effectiveness, 20 RNA isolates from COVID-19 patients were selected and distributed into four groups according to $\mathrm{Ct}$ values obtained from RTqPCR: group 1(n=6), RT-qPCR-positive for both ORF1ab $(\mathrm{Ct} \leq 30 \mathrm{~min})$ and $\mathrm{E} / \mathrm{N}$ genes; group 2 ( $\mathrm{n}=6)$, RT-qPCR-positive for both $\mathrm{ORF} 1 \mathrm{ab}(\mathrm{Ct}>30 \mathrm{~min})$ and $\mathrm{E} / \mathrm{N}$ genes; group 3 $(n=2)$, RT-qPCR-positive for ORF1ab and RT-qPCR-negative for gen E; group $4(n=6)$, RT-qPCR-negative for ORF1ab and RT-qPCR-positive for N gene. Groups of samples, $\mathrm{Ct}$ values for amplified targets, and commercial kits used in RT-qPCR are indicated in Table 2 (Tab. 2).

\section{RT-LAMP primer design}

Primer sets used for LAMP were based on the SARS-CoV-2 complete genome sequence from the NCBI nucleotide database (GenBank: MN908947.3) ${ }^{35}$ to target specific regions in ORF1ab, ORF1b, S, E, M, and N genes. The primer set used to target the conserved sequence of ORF1ab was previously described by El-Tholoth et al. ${ }^{24}$. Primer sets targeting ORF1b and S genes were designed in house based upon recently reported sequences used for RT-qPCR detection of SARS-CoV-2 by Wu et al. ${ }^{35}$. Primer sets targeting E, M, and $\mathrm{N}$ genes were in house designs. All primer sets were designed using the open access Primer Explorer V5 software tool (Eiken Chemical Co., Ltd., Japan) at the website: https://primerexplorer.jp/e/. Once the best parameters have been considered, a single primer set was selected for ORF1ab, ORF1b, E, and M genes; for S (S447, S555) 
and N (N5, N15) genes two primer sets targeting different regions were selected. Each primer set included two outer primers (F3 and B3), two inner primers (FIP and BIP) and, for ORF1ab, S447, N5 and N15 primer sets, two additional loop primers (LF and LB) were designed and selected. All the primers were synthesized (synthesis scale, 0.025 $\mu$ mol; purification, desalt; solution, water) by Eurofins Genomics (Ebersber, Germany). The localization of LAMP targets on the genome of SARS-CoV-2 is represented in Figure 1 (Fig. 1). Sequences of the oligonucleotide primer sets finally selected are listed in Tab. 1.

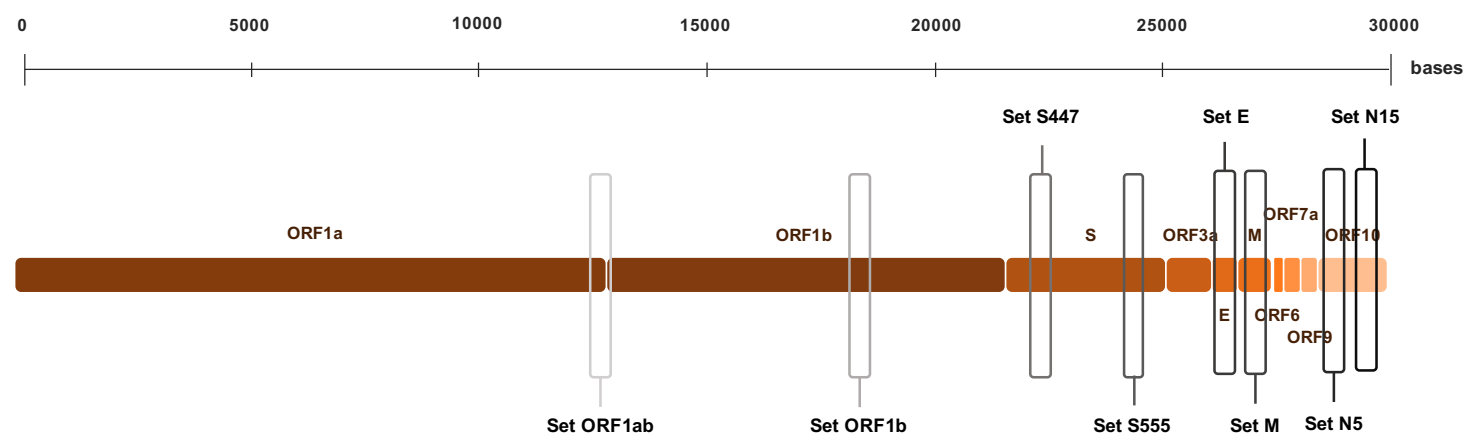

Figure 1. Schematic representation of COVID-LAMP target localization within SARS-CoV-2 genome. Genbank sequence accession number: MN908947.335 
Table 1. Primer sets used in this study for the detection of SARS-Cov-2 through reverse transcription loop-mediated isothermal amplification (RT-LAMP).

\begin{tabular}{|c|c|c|c|c|}
\hline Set & Primer & Sequence $5^{\prime} \rightarrow 3^{\prime}$ & $\begin{array}{c}\text { Length } \\
\text { (nt) }\end{array}$ & $\begin{array}{c}\text { Gene } \\
\text { position }\end{array}$ \\
\hline \multirow{6}{*}{ ORF1ab ${ }^{\mathrm{a}}$} & F3 & TGCTTCAGTCAGCTGATG & 18 & \multirow{6}{*}{$13434-13636$} \\
\hline & $\mathrm{B} 3$ & TTAAATTGTCATCTTCGTCCTT & 22 & \\
\hline & FIP & CAGTACTAGTGCCTGTGCCGCACAATCGTTTTTAAACGGGT & 41 & \\
\hline & BIP & TCGTATACAGGGCTTTTGACATCTATCTTGGAAGCGACAACAA & 43 & \\
\hline & LF & CTGCACTTACACCGCAA & 17 & \\
\hline & LB & GTAGCTGGTTTTGCTAAATTCC & 22 & \\
\hline \multirow{4}{*}{ ORF $1 b^{b}$} & F3 & CACAGACTTTGTGAATGAGTT & 21 & \multirow{4}{*}{$15654-15896$} \\
\hline & B3 & GTCAGTCTCAGTCCAACAT & 19 & \\
\hline & FIP & CTATTGAAACACACAACAGCATCGCATATTTGCGTAAACATTTCTCA & 47 & \\
\hline & BIP & TATGCATCTCAAGGTCTAGTGGCTATGCTTCAGACATAAAAACATTG & 47 & \\
\hline \multirow{6}{*}{$\mathrm{S} 447^{\mathrm{b}}$} & F3 & GTTTCTGCCTTTCCAACAA & 19 & \multirow{6}{*}{$22985-23415$} \\
\hline & B3 & AACAGGGACTTCTGTGCA & 18 & \\
\hline & FIP & TCAAGAATCTCAAGTGTCTGTGGTGGCAGAGACATTGCTGA & 41 & \\
\hline & BIP & ACCATGTTCTTTTGGTGGTGTCAACATCCTGATAAAGAACAGC & 43 & \\
\hline & LF & TCACGGACAGCATCAGTAGTG & 21 & \\
\hline & LB & CAGGAACAAATACTTCTAACCAGGT & 25 & \\
\hline \multirow{4}{*}{$\mathrm{S} 555^{\mathrm{b}}$} & F3 & CTATGCAAATGGCTTATAGGTT & 22 & \multirow{4}{*}{$24182-24736$} \\
\hline & B3 & AGTTGTTTAACAAGCGTGTT & 20 & \\
\hline & FIP & GCACTATTAAATTGGTTGGCAATCATAATGGTATTGGAGTTACACAGA & 48 & \\
\hline & BIP & ATTGGCAAAATTCAAGACTCACTTTTGTGCATTTTGGTTGACC & 43 & \\
\hline \multirow{4}{*}{$\mathrm{E}^{\mathrm{c}}$} & F3 & TCATTCGTTTCGGAAGAGA & 19 & \multirow{4}{*}{$26245-26472$} \\
\hline & $\mathrm{B} 3$ & AGGAACTCTAGAAGAATTCAGAT & 23 & \\
\hline & FIP & TGTAACTAGCAAGAATACCACGAAACAGGTACGTTAATAGTTAATAGCG & 49 & \\
\hline & BIP & GCTTCGATTGTGTGCGTACTCGAGAGTAAACGTAAAAAGAAGG & 43 & \\
\hline \multirow{4}{*}{$\mathrm{M}^{\mathrm{c}}$} & F3 & GTTTCCTATTCCTTACATGGATT & 23 & \multirow{4}{*}{$26597-26801$} \\
\hline & B3 & AGCCACATCAAGCCTACA & 18 & \\
\hline & FIP & CCATAACAGCCAGAGGAAAATTAACCTTCTACAATTTGCCTATGCC & 46 & \\
\hline & BIP & AACTTTAGCTTGTTTTGTGCTTGCACAAGCCATTGCGATAGC & 42 & \\
\hline \multirow{6}{*}{$\mathrm{N} 5^{\mathrm{c}}$} & F3 & CCAGAATGGAGAACGCAGTG & 20 & \multirow{6}{*}{$28355-28570$} \\
\hline & B3 & CCGTCACCACCACGAATT & 18 & \\
\hline & FIP & AGCGGTGAACCAAGACGCAGGGCGCGATCAAAACAACG & 38 & \\
\hline & BIP & AATTCCCTCGAGGACAAGGCGAGCTCTTCGGTAGTAGCCAA & 41 & \\
\hline & LF & ATTATTGGGTAAACCTTGGGGC & 22 & \\
\hline & LB & ATTAACACCAATAGCAGTCCAGATG & 25 & \\
\hline \multirow{6}{*}{$\mathrm{N} 15^{\mathrm{c}}$} & F3 & AGATCACATTGGCACCCG & 18 & \multirow{6}{*}{$28703-28915$} \\
\hline & B3 & CCATTGCCAGCCATTCTAGC & 20 & \\
\hline & FIP & TGCTCCCTTCTGCGTAGAAGCCAATGCTGCAATCGTGCTAC & 41 & \\
\hline & BIP & GGCGGCAGTCAAGCCTCTTCCCTACTGCTGCCTGGAGTT & 39 & \\
\hline & LF & GCAATGTTGTTCCTTGAGGAAGTT & 24 & \\
\hline & LB & CCTCATCACGTAGTCGCAACAG & 22 & \\
\hline
\end{tabular}

F3, forward primer; B3, backward primer; BIP, backward inner primer; FIP, forward inner primer;

LB, loop backward; LF, loop forward

${ }^{a}$ Primer set previously described by El-Tholoh et $a l .^{28}$

${ }^{\mathrm{b}}$ Primer sets designed in house based upon sequences used for RT-qPCR detection of SARS-CoV-2 by Wu et al. ${ }^{30}$

${ }^{c}$ Primer sets designed in house

\section{RT-LAMP reaction}

For the one-step RT-LAMP reaction, two reaction mixtures containing different polymerases were evaluated. On one hand, RT-LAMP assay was performed using Bst 3.0 DNA Polymerase (Bst 3.0) (New England Biolabs Ltd., UK) for both isothermal amplification performance and reverse transcription. On the other hand, RT-LAMP assays were performed in the presence of two enzymes: Bst 2.0 WarmStart $^{\circledR}$ DNA Polymerase (Bst 2.0 WS) and WarmStart ${ }^{\circledR} R T x$ Reverse Transcriptase (RTx WS) (New 
England Biolabs Ltd., UK). Briefly, RT-LAMP reaction mixtures (15 $\mu \mathrm{L})$ contained 1.6 $\mu \mathrm{M}$ FIP/BIP, $0.2 \mu \mathrm{M}$ F3/B3, $0.4 \mu \mathrm{M} \mathrm{LF} / \mathrm{LB}$ (if applicable), $1.4 \mathrm{mM}$ of each dNTP, (Bioron GmBH, Germany) 0.13 M of D-(+)-Trehalose dihydrate (Sigma-Aldrich, USA) (from now on, trehalose), $6 \mathrm{mM} \mathrm{MgSO}_{4}$, and 1x Isothermal Amplification Buffer II (20 $\mathrm{mM}$ Tris- $\mathrm{HCl}$ ( $\mathrm{pH} 8.8$ ), $150 \mathrm{mM} \mathrm{KCl}, 10 \mathrm{mM}$ (NH4)2SO4, $2 \mathrm{mM} \mathrm{MgSO} 4,0.1 \%$ Tween20) for Bst 3.0 DNA polymerase $(0.32 \mathrm{U} / \mu \mathrm{L})$ or $1 \mathrm{x}$ Amplification Buffer $(20 \mathrm{mM}$ Tris- $\mathrm{HCl}(\mathrm{pH} 8.8), 50 \mathrm{mM} \mathrm{KCl}, 10 \mathrm{mM}(\mathrm{NH} 4)_{2} \mathrm{SO}_{4}, 2 \mathrm{mM} \mathrm{MgSO}_{4}, 0.1 \%$ Tween20) for Bst $2.0 \mathrm{WS}(0.32 \mathrm{U} / \mu \mathrm{L})$ and $R T x$ WS $(0.3 \mu \mathrm{L})$, with $1 \mu \mathrm{L}$ of template RNA $(\mathrm{C}+$, for positive control; ultrapure water for negative control). To establish the optimal reaction conditions, the one-step RT-LAMP assay was real-time evaluated at different temperatures and reaction times in 8-tube Genie Strips on a portable Genie III device (Optigene Ltd., Horsham, UK) adding $0.24 \mu \mathrm{L}$ of EvaGreen 20X in water (Biotium, USA) to the reaction mix. For Bst 3.0 reactions, temperatures ranging $62^{\circ} \mathrm{C}$ to $72^{\circ} \mathrm{C}$ (in $2^{\circ} \mathrm{C}$ increments) and reaction times of 45, 60 and 80 min were tested. For Bst 2.0 WS and RTx WS reactions, different temperatures $\left(63^{\circ} \mathrm{C}, 64^{\circ} \mathrm{C}, 65^{\circ} \mathrm{C}\right)$ and reaction times $(45,60,80$ $\min )$ were also tested.

In addition, conventional colorimetric one-step RT-LAMP reactions were also performed with Bst 2.0 WS and RTx WS in a heating block. Results were visually inspected by the naked eye based on the colour change observed (green for a positive result and orange for a negative result) with $1 \mu \mathrm{L}$ of SYBR ${ }^{\circledR}$ Green I $1000 \times$ (Invitrogen, USA) added postamplification to each tube.

\section{Specificity and sensitivity assessment}

To confirm the specificity of the evaluated primers a BLASTN local search and alignment analysis was carried out in GenBank online databases (NCBI; http://blast.ncbi.nlm.nih.gov/Blast.cgi) against currently available nucleotide sequences for other human respiratory viruses and other human-infecting viruses. Comparison included: Influenza A virus (taxid:11320), Influenza B virus (taxid:11520), Human parainfluenza virus 1 strain Washington/1964 (taxid:188538), Human parainfluenza virus 2 (strain Toshiba) (taxid:11214), Human parainfluenza virus 4a (taxid:11224), Human adenovirus 4a (taxid:35263), Human adenovirus 7 (taxid:10519), Enterovirus A (taxid:138948), Enterovirus B (taxid:138949), Enterovirus C (taxid:138950), Metapneumovirus (taxid:162387), Respiratory Syncytial Virus (taxid:12331), Zika virus 
(taxid:64320), Dengue virus (taxid:12637), Chikungunya virus (taxid:37124), and Middle East respiratory syndrome-related coronavirus (MERS-CoV) (taxid:1335626).

Additionally, the RT-LAMP primer sets were cross-tested for specificity against a panel of 13 RNA isolates of related coronaviruses obtained from patients infected with Coronavirus NL63, Coronavirus OC43, Bocavirus, Rinovirus, Metapneumovirus, Respiratory Syncytial Virus A, Respiratory Syncytial Virus B, Enterovirus, Parainfluenzae 1, Influenza H1N1, Influenza A H3, Influenza A H1, and Influenza B. These RNA isolates were provided by the laboratory of the National Influenza Centre of Valladolid (University Clinical Hospital of Valladolid, Valladolid, Castilla y León, Spain). This laboratory is part of a network of 126 laboratories around the world linked to the WHO responsible for the characterization and diagnosis of circulating influenza viruses.

To assess the analytical sensitivity of the primer sets in the detection of SARS-CoV-2, serial dilutions (10-fold) of the $\mathrm{C}+$ in nuclease-free water (diluted from $1 \times$ to $10^{-4}$ ) were prepared and used to determine the limit of detection of the RT-LAMP assays.

\section{Stabilization for long-term room-temperature storage: Dry-RT-LAMP}

We optimized the RT-LAMP reaction protocol for potential ready-to-use COVID-19 RTLAMP test. For long-term room temperature storage, the master mixes containing the two enzymes and primer sets ORF1ab, N5, or N15 were stabilized by a vacuum process without centrifugation (so called, desiccation) in a Concentrator Plus (EPPENDORF, Germany) at RT for $30 \mathrm{~min}$, following a single dry-up step as previously described elsewhere ${ }^{11}$, with some modifications. In brief, RT-LAMP master mixes were dried in open 8-tube Genie Strips (OPTIGENE, UK) separately in two partial mixes: one containing primers, dNTPs, and polymerases placed in the bottom of the tube in the presence of $1.8 \mu \mathrm{L}$ of trehalose $2 \mathrm{M}$; other containing Isothermal Buffer $10 \mathrm{x}, \mathrm{MgSO}_{4}$, and $0.24 \mu \mathrm{L}$ EvaGreen $10 \mathrm{X}$ in the tube cap in the presence of $2.25 \mu \mathrm{L}$ of trehalose $2 \mathrm{M}$. The desiccation procedure yielded two stable and well-adhered pellets in both cap and bottom of the tubes. To estimate the stability and functionality over time, the desiccated 8-tube strips were stored at $25^{\circ} \mathrm{C}, 37^{\circ} \mathrm{C}$, and $45^{\circ} \mathrm{C}$ for up to 28 days in paperboard storage boxes with some Silica Gel desiccant pouches inside to protect against moisture until use. After rehydration with ultrapure water (for negative controls) or ultrapure water containing 
RNA (for C+ or RNA samples), the real-time RT-LAMP assays with Genie III were performed at $63^{\circ} \mathrm{C}$ for up to $120 \mathrm{~min}$ at $0,1,7,14,21$, and 28 days post-desiccation.

\section{Estimation of the shelf-life of the Dry-RT-LAMP mixes}

To estimate the shelf-life of the dry-reagents RT-LAMP mixes the accelerated ageing technique (also known as $\mathrm{Q}_{10}$ method) described by Clark (1991) was employed ${ }^{36}$. The shelf-life can be determined by either a real-time or an accelerated ageing test where Arrhenius Law is applied in a simulated environment. The method was conducted by exposing the dry-reagents RT-LAMP mixes to different temperatures $\left(25^{\circ} \mathrm{C}, 37^{\circ} \mathrm{C}, 45^{\circ} \mathrm{C}\right)$ for up to 28 days and assessing the functionality of the dried RT-LAMP reagents periodically, at $0,1,7,14,21$, and 28 days post-desiccation. Data obtained were used to calculate the assay stability at RT $\left(25^{\circ} \mathrm{C}\right)$ with the following formulas:

$$
\begin{gathered}
A F=Q_{10}^{[0.1 \times(T e-T a)]} \\
A G=\mathrm{t}_{\mathrm{e}} \times A F \\
\text { Estimated Shelf }- \text { life }=A G+t_{e}
\end{gathered}
$$

where, AF is the acceleration factor used to correlate the shelf-life of the product at a lower temperature than the one used to perform the experiment; $\mathrm{Q}_{10}$ factor measures the temperature sensitivity of an enzymatic reaction rate due to an increase by $10^{\circ} \mathrm{C} ; \mathrm{T}_{\mathrm{e}}$ represents the elevated temperature; $A G$ is the accelerated age; $t_{e}$ is the length of time storage at elevated temperature, and $\mathrm{T}_{\mathrm{a}}$ is the ambient temperature $\left(\mathrm{RT} ; 25^{\circ} \mathrm{C}\right)$. Since for most biological reactions $\mathrm{Q}_{10} \sim 2$ or $3^{37}$, we established a conservative value for $\mathrm{Q}_{10}=1.9$ to perform all the calculations. The evaluation of the estimated shelf-life was performed for dried master mixes mentioned above for up to 28 days using $\mathrm{C}+$ as template. Additionally, dried N15-RT-LAMP master mixes for up to one week were also tested using RNA isolates as templates.

\section{RESULTS}

\section{RT-LAMP primer sets screening and selection}

The first screening of each primer set designed was performed using the Bst 3.0 DNA polymerase in real-time conditions to amplify $\mathrm{C}+$ template at different temperatures and 
reaction times described in the 'Methods' section. Frequently, non-specific amplification was obtained, and results were rather irregular and not reproducible. Therefore, further use in RT-LAMP amplification of SARS-CoV-2 RNA was discarded.

The second screening of each primer set was also performed in real-time conditions using the combination of the Bst $2.0 \mathrm{WS}$ and $R T x \mathrm{WS}$. After testing different RT-LAMP conditions, a reaction time of $60 \mathrm{~min}$ at $63^{\circ} \mathrm{C}$ plus $5-10 \mathrm{~min}$ of inactivation was considered the most appropriate for performance comparison among primer sets. Subsequently, the accuracy and efficiency of each primer set was evaluated through RT-LAMP using C+ as template in duplicate. Results obtained are shown in Fig. 2. Four of the eight primer sets were selected for further evaluation based on the lowest threshold time -thus meaning the fastest amplification-, reproducibility and the absence of non-specific amplifications: set ORF1 ab $(\mathrm{Ct}=20.5 \mathrm{~min})$, set $\mathrm{E}(\mathrm{Ct}=43.5 \mathrm{~min})$, set N5 $(\mathrm{Ct}=19 \mathrm{~min})$, and set N15 $(\mathrm{Ct}=15$ min). The remaining primer sets were discarded for further assessment because of relatively early non-specific amplifications (set ORF1b), failed amplification (set S447), poor amplification and reproducibility (set M), or high threshold value (set S555).
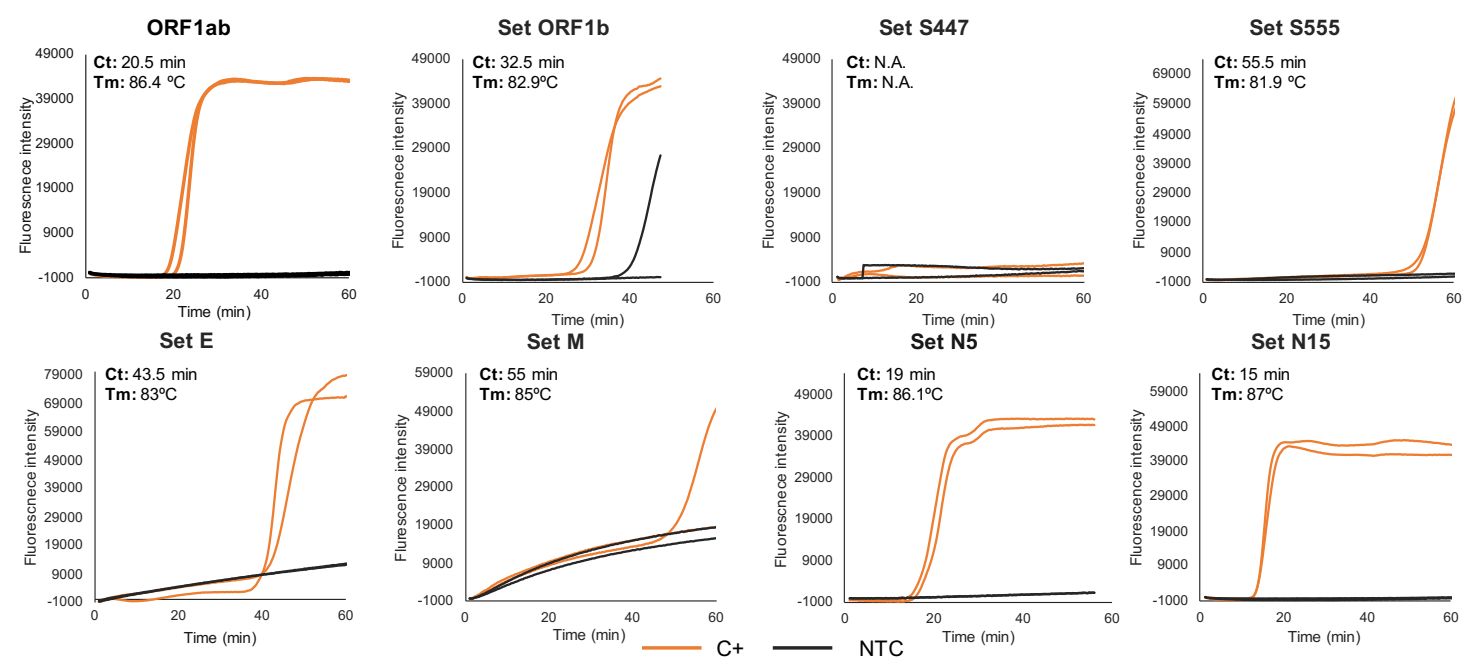

Figure 2. Real-time RT-LAMP assays performed using the eight primers sets evaluated for the detection of SARS-CoV-2. EvaGreen 20x fluorescence signal over time for primer sets ORF1ab, ORF1b, S447, S555, E, M, N5, and N15 is shown. Orange lines $(\mathrm{C}+$, positive control); black lines (NTC, non-template control). Threshold values $(\mathrm{Ct} ; \mathrm{min})$ and melting temperatures $\left(\mathrm{Tm} ;{ }^{\circ} \mathrm{C}\right)$ for each primer set are indicated. All reactions were performed in duplicates. 


\section{Specificity and sensitivity of RT-LAMP}

No significant similarity between targets selected for SARS-CoV-2 detection and other sequences reported for possible human-infecting viruses were in silico detected when searching in databases. Furthermore, no RNA isolate from patients infected with related coronaviruses was amplified when using the selected primer sets that resulted most efficient in amplifying SARS-CoV-2 RNA (set ORF1ab, set E, set N5, set N15), thus indicating the high specificity of the established RT-LAMP assays (Fig.3).
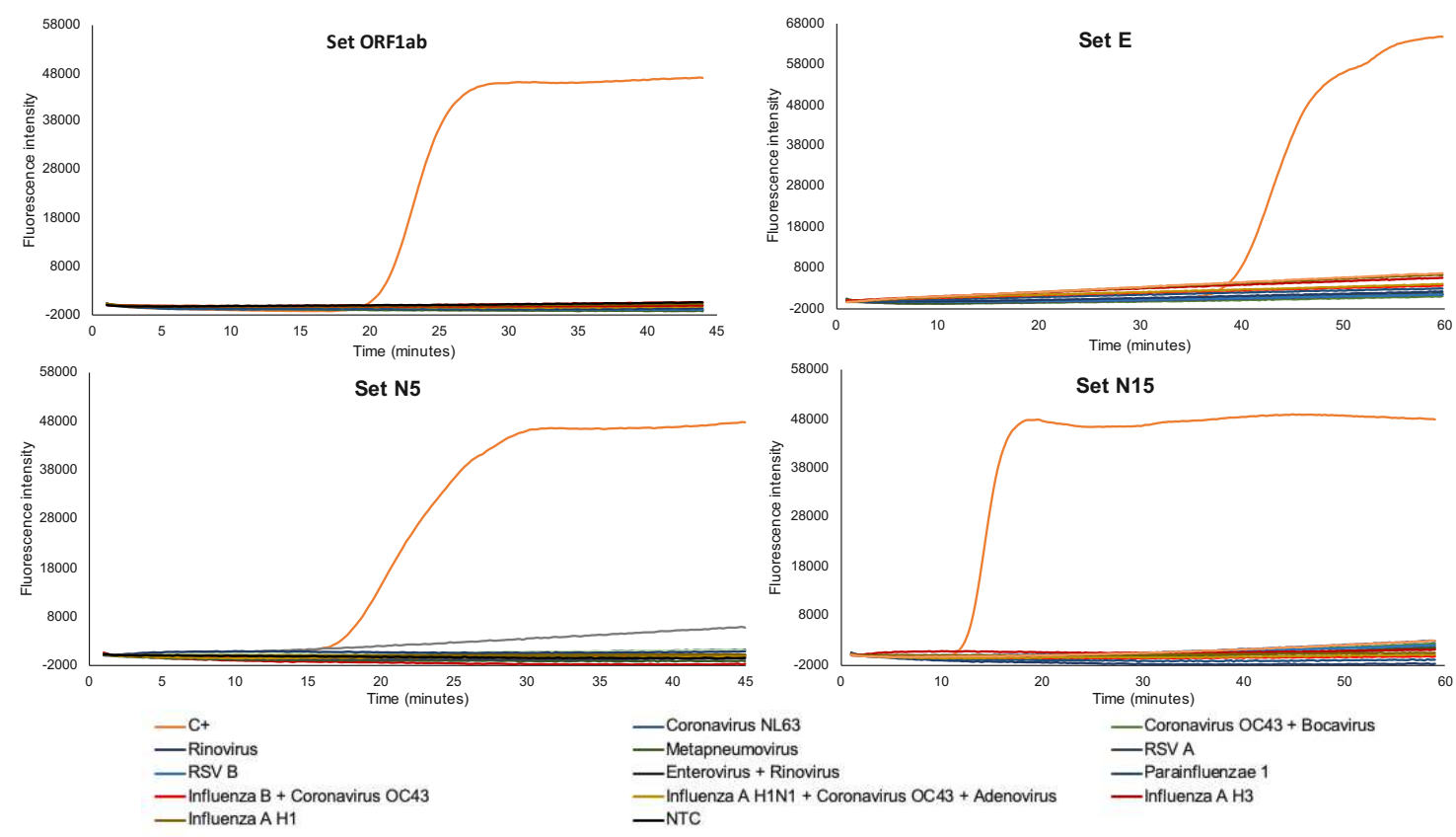

Figure 3. Specificity assessment of the RT-LAMP assays for SARS-CoV-2 RNA detection using primer sets ORF1ab, E, N5 and N15. A panel of 13 purified RNA isolates of related virus obtained from infected patients are included: Coronavirus NL63, Coronavirus OC43, Bocavirus, Rinovirus, Metapneumovirus, Respiratory Syncytial Virus A, Respiratory Syncytial Virus B, Enterovirus, Parainfluenzae 1, Influenza H1N1, Influenza A H3, Influenza A H1, and Influenza B. One sample contained RNA from two virus (Influenza B + Coronavirus OC43); other sample contained RNA from three virus (Influenza A H1 + Coronavirus OC43 + Adenovirus).

Regarding to the sensitivity of the RT-LAMP assays, 10-fold serial dilutions of C+ was amplified by real-time RT-LAMP to determine the lower limit of detection. Analytical sensitivities for selected primer sets ORF1ab, E, N5, and N15 are shown in Fig. 4. The results indicated that RT-LAMP assays using sets ORF1ab, N5 and N15 were 10 times 
more sensitive than RT-LAMP assay using set E (1:100 vs 1:10 dilution, respectively). According to this, an approximate limit of detection of $2 \times 10^{2} \mathrm{cpr}$ for RT-LAMP using sets ORF1ab, N5 and N15, and $2 \times 10^{3}$ cpr for RT-LAMP using set E was established.
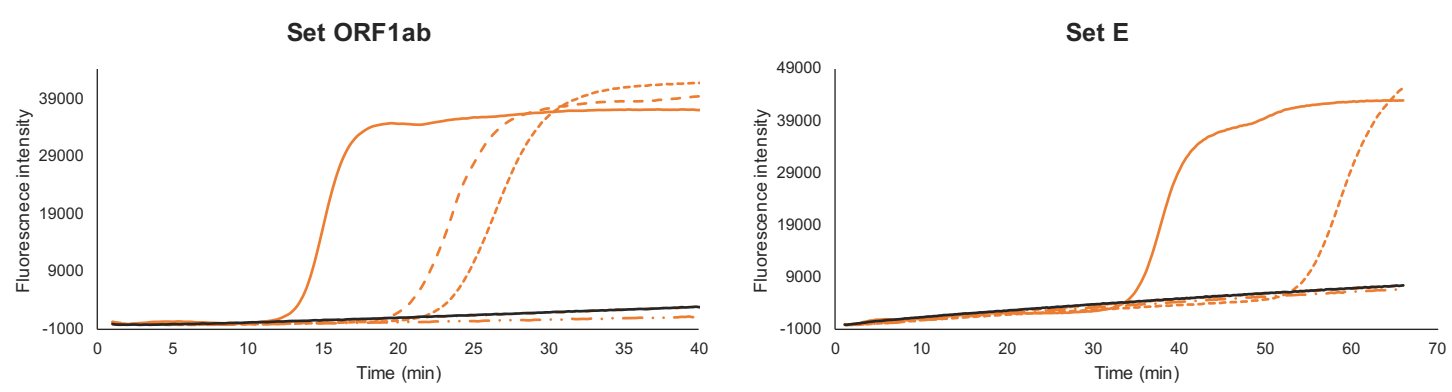

Set N5
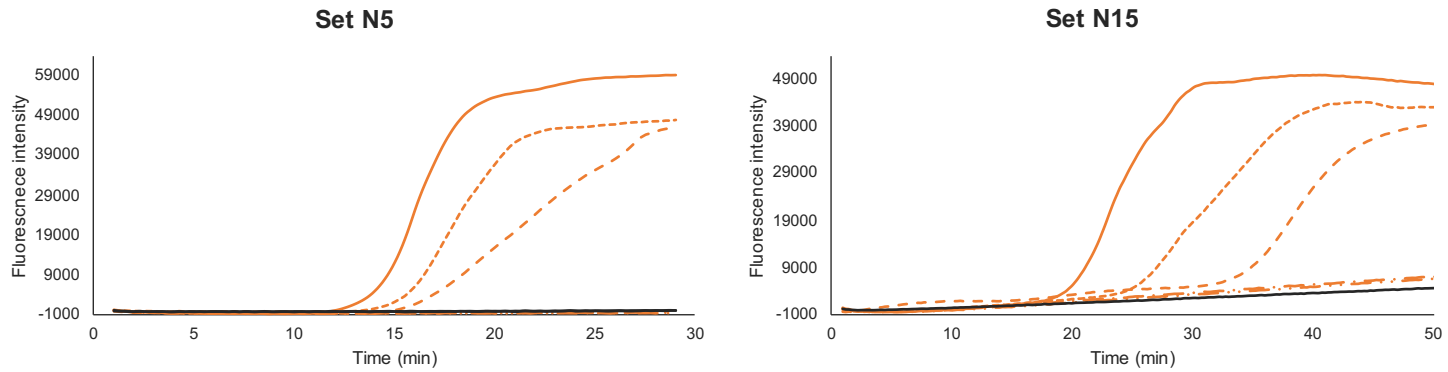

— $1 \mathrm{x}-\cdots 1: 10--1: 10^{2}-\cdot-1: 10^{3}-\cdots 1: 10^{4}-$ NTC

Figure 4. Sensitivity assessment of the RT-LAMP assays for SARS-CoV-2 RNA detection using primer sets ORF1ab, E, N5 and N15. The 10-fold dilutions (1x-1:10 $\left.{ }^{4}\right)$ of positive control $(\mathrm{C}+)$ are represented by orange lines; non-template control (NTC) is represented by black lines.

\section{Clinical samples testing}

Based on the previous analysis of RT-qPCR, 20 RNA isolates from COVID-19 patients were analyzed by RT-LAMP with the most efficient primer sets in this study: set ORF1ab, set E, set N5 and set N15. Comparison of the Ct values obtained by RT-qPCR and RTLAMP assays are shown in Tab. 2. When testing the six RT-qPCR-positive samples of group $1(\mathrm{ORF} 1 \mathrm{ab}+; \mathrm{Ct} \leq 30 / \mathrm{E}+$ or $\mathrm{N}+$ ) the RT-LAMP assays using primer sets ORF1ab, N5, and N15, each detected 6/6 (100\% sensitivity) with lower Ct values for all samples than those obtained by RT-qPCR. The RT-LAMP using primer set E detected 5/6 samples ( $83.3 \%$ sensitivity), with a high $\mathrm{Ct}=72 \mathrm{~min}$ for sample 2 , the only one tested by cobas ${ }^{\circledR}$ $\mathrm{RT}-\mathrm{qPCR}$ for gene $\mathrm{E}(\mathrm{Ct}=26 \mathrm{~min})$ in this group. The $\mathrm{Ct}$ values for the four remaining 
positive samples for gene E resulted equal or higher than those of the VIASURE RTqPCR for $\mathrm{N}$ gene.

When testing the six RT-qPCR-positive samples of group 2 (ORF1ab+; $\mathrm{Ct}>30 / \mathrm{E}+$ or $\mathrm{N}+$ ) the RT-LAMP using primer set ORF1ab detected 4/6 samples (66.6\%) with lower (nos. 7, 9, and 10) or similar (no. 8) Ct values than those obtained by RT-qPCR for both the ORF1ab and the E/N targets. The RT-LAMP using primer set N5 detected 3/6 samples $(50 \%)$ with much lower $\mathrm{Ct}$ values (nos. $7,8,9)$ than those obtained for RT-qPCR. The RT-LAMP using primer set N15 amplified 6/6 (100\%) samples with relatively high Ct values for samples $8(\mathrm{Ct}=49 \mathrm{~min}), 10(\mathrm{Ct}=60 \mathrm{~min})$ and $11(\mathrm{Ct}=45 \mathrm{~min})$ in comparison to those obtained by RT-qPCR. For samples nos. 9 and 12, the Ct values were similar than RT-qPCR results $(\mathrm{Ct}=39 \mathrm{~min}$ and $\mathrm{Ct}=36 \mathrm{~min}$, respectively). For no. 7, a very low $\mathrm{Ct}=13$ min was obtained. The RT-LAMP using primer set E only amplified 1/6 samples (16.6\%) (sample no. 7), with a $\mathrm{Ct}=60 \mathrm{~min}$, a value much higher than the one obtained by $\mathrm{RT}$ qPCR.

The samples nos. 13 and 14 of the group 3 (ORF1ab+; Ct>30/E-) were amplified by RTLAMP using the primer set ORF1ab with very similar $\mathrm{Ct}$ values than RT-qPCR. The primer set $\mathrm{N} 5$ amplified the sample no. 14 with a very low $\mathrm{Ct}=18 \mathrm{~min}$ in comparison to $\mathrm{Ct}=33$ min obtained for OFR1ab by RT-qPCR. The primer set N15 amplified the two samples, but not the primer set E.

When testing the six samples included in the group $4(\mathrm{ORF} 1 \mathrm{ab}-\mathrm{N}+)$, the primer set ORF 1ab amplified 3 samples (nos. 15, 16, 18). The primer set N15 detected 5/6 samples $(86.3 \%)$ that resulted $\mathrm{N}+$ by VIASURE RT-qPCR, nevertheless, the primer set N5 did not amplify any sample. The primer set E, either. In all, considering the few positive results obtained with the primer set E (6/12 confirmed positives (both PCR targets positives); 50\%) this RT-LAMP assay was discarded for further testing. 
Table 2. Comparison of the results of Ct values obtained by RT-qPCR and RTLAMP assays using primer sets ORF1ab, N5, N15, and E in testing 20 RNA isolates from COVID-19 patients. Groups of samples, commercial Real Time PCR Detection Kits targeting ORF1ab and E/N used in RT-qPCR tests, and primer sets evaluated for RTLAMP assays are indicated. $\mathrm{Ct}$ values are indicated in minutes.

\begin{tabular}{|c|c|c|c|c|c|c|c|c|}
\hline \multirow[b]{2}{*}{ Groups } & \multirow[b]{2}{*}{ No. sample } & \multicolumn{3}{|c|}{$\begin{array}{l}\text { RT-qPCR } \\
\text { Ct values }\end{array}$} & \multicolumn{4}{|c|}{$\begin{array}{c}\text { Real-time RT-LAMP } \\
\text { Ct values }\end{array}$} \\
\hline & & $\begin{array}{c}\text { Commercial } \\
\text { kit }\end{array}$ & ORF1ab & $E / \mathbf{N}$ & ORF1ab & N5 & N15 & $\mathbf{E}$ \\
\hline \multirow[t]{2}{*}{ Group 1} & 1 & Viasure & 22 & 27 & 15 & 14 & 9 & 27 \\
\hline & 2 & $\operatorname{cobas}^{\circledR}$ & 25 & 26 & 18 & 16 & 13 & 72 \\
\hline \multirow{2}{*}{$\begin{array}{c}\text { ORF1ab+ } \\
(\mathrm{Ct}<30)\end{array}$} & 3 & Viasure & 25 & 29 & 15 & 15 & 19 & 43 \\
\hline & 4 & Viasure & 26 & 25 & 17 & 16 & 11 & 28 \\
\hline \multirow[t]{2}{*}{$\mathrm{E} / \mathrm{N}+$} & 5 & Viasure & 27 & 31 & 17 & 18 & 13 & - \\
\hline & 6 & Viasure & 27 & 30 & 19 & 18 & 13 & 35 \\
\hline \multirow[t]{2}{*}{ Group 2} & 7 & Viasure & 32 & 31 & 20 & 22 & 13 & 60 \\
\hline & 8 & $\operatorname{cobas}^{\circledR}$ & 32 & 35 & 35 & 23 & 49 & - \\
\hline \multirow{2}{*}{$\begin{array}{c}\text { ORF1ab+ } \\
(\mathrm{Ct}>30)\end{array}$} & 9 & Viasure & 33 & 39 & 23 & 20 & 39 & - \\
\hline & 10 & $\operatorname{cobas}^{\circledR}$ & 33 & 36 & 31 & - & 60 & - \\
\hline \multirow[t]{2}{*}{$\mathrm{E} / \mathrm{N}+$} & 11 & $\operatorname{cobas}^{\circledR}$ & 34 & 36 & - & - & 45 & - \\
\hline & 12 & Viasure & 39 & 36 & - & - & 36 & - \\
\hline \multirow{3}{*}{$\begin{array}{c}\text { Group } 3 \\
\text { ORF1ab+ } \\
\text { E- }\end{array}$} & 13 & cobas $^{\mathbb{B}}$ & 36 & - & 39 & - & 29 & - \\
\hline & & & & & & & & \\
\hline & 14 & cobas $^{\mathbb{R}}$ & 33 & - & 30 & 18 & 47 & - \\
\hline \multirow[t]{2}{*}{ Group 4} & 15 & Viasure & - & 25 & 34 & - & 46 & - \\
\hline & 16 & Viasure & - & 38 & 28 & - & 31 & - \\
\hline \multirow{4}{*}{$\begin{array}{l}\text { ORF1ab- } \\
\mathrm{N}+\end{array}$} & 17 & Viasure & - & 38 & - & - & - & - \\
\hline & 18 & Viasure & - & 40 & 43 & - & 60 & - \\
\hline & 19 & Viasure & - & 41 & - & - & 58 & - \\
\hline & 20 & Viasure & - & 41 & - & - & 30 & - \\
\hline
\end{tabular}

To evaluate the conventional colorimetric RT-LAMP assay we selected 8 RNA isolates representing the four groups of samples used in the study: samples nos. 4, 5, 6 (ORF1ab+; $\mathrm{Ct} \leq 30 / \mathrm{E}+$ or $\mathrm{N}+)$; samples nos. 7, $12(\mathrm{ORF} 1 \mathrm{ab}+$; $\mathrm{Ct}>30 / \mathrm{E}+$ or $\mathrm{N}+)$; sample no. 14 $(\mathrm{ORF} 1 \mathrm{ab}+\mathrm{E}+)$, and samples nos. 15, $16(\mathrm{ORF} 1 \mathrm{ab}-\mathrm{N}+)$. The samples were tested using the primer sets ORF1ab, N5, and N15. The performance of each RT-LAMP assay is shown in Figure 5 (Fig. 5). Green fluorescence was clearly observed in the successful RT-LAMP reactions, while it remained original orange in the negative reactions. For the 
selected samples, the color change matched $100 \%$ with the results obtained in real-time RT-LAMP assays.
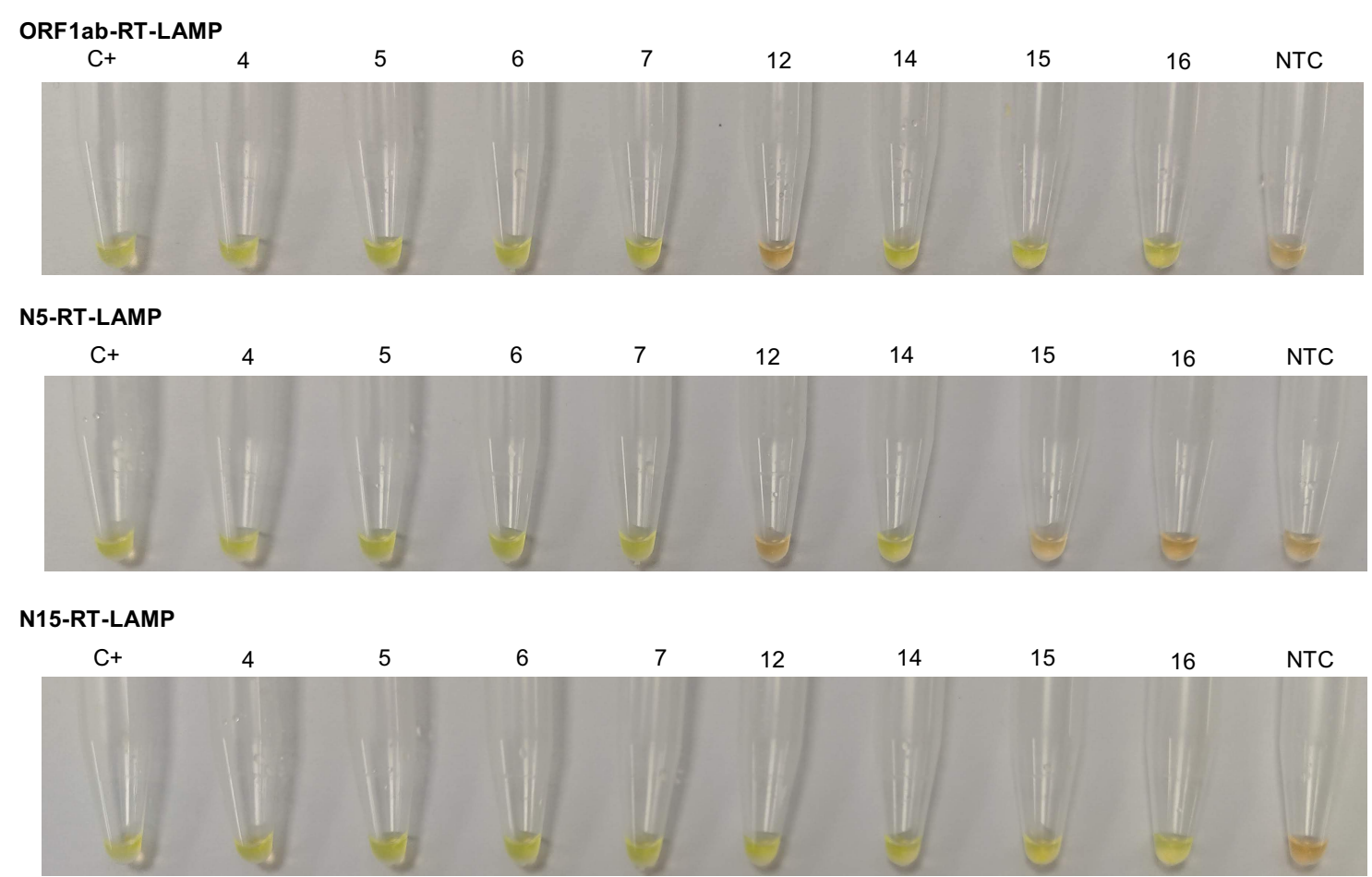

Figure 5. Conventional colorimetric RT-LAMP assays using the primer sets ORF1ab, N5, and N15. Eight RNA isolates from COVID-19 patients (samples nos. 4, 5, $6,7,12,14,15$, and 16 ) were analyzed by colorimetric RT-LAMP using SYBR ${ }^{\circledR}$ Green fluorescent dye. Green (positive samples), orange (negative samples). C+, RNA-positive control; NTC, non-template control.

\section{Stability and functionality over time of Dry-RT-LAMP mixes}

As the primer sets ORF1ab, N5, and N15 offered the best results in the amplification of the COVID-19 patients' RNA isolates they were selected for further stabilization assays. The results obtained in Dry-RT-LAMP tests for each primer set are shown in Figure 6. In general, reconstitution of dry reagents worked well, and amplification was obtained for the three primer sets used at RT $\left(25^{\circ} \mathrm{C}\right)$, but a delay in amplification during the reaction for dried mixtures was observed in comparison to fresh mixes. Thus, just after desiccation of reagents (at day 0) an increase in $\mathrm{Ct}$ values was noticed for primer sets ORF1 ab (Ct $=20.5 \mathrm{~min}$ to $\mathrm{Ct}=32 \mathrm{~min})$ and $\mathrm{N} 5(\mathrm{Ct}=19 \mathrm{~min}$ to $\mathrm{Ct}=29 \mathrm{~min})$. Significantly, no variation of $\mathrm{Ct}$ value was registered for primer set $\mathrm{N} 15$ after desiccation $(\mathrm{Ct}=15 \mathrm{~min})$. Despite the 
increase in $\mathrm{Ct}$ values over time, storage of dry-reagent RT-LAMP assays at RT was found to be functional for 14, 21 and 28 days when using primer sets ORF1ab, N5, and N15, respectively. Remarkably, the Dry-N15-RT-LAMP assay proved to be stable up to 28 days with a very reasonable $\mathrm{Ct}=80 \mathrm{~min}$. According to values of the stability times obtained at $37^{\circ} \mathrm{C}$ (21 days) and $45^{\circ} \mathrm{C}$ (14 days), the $\mathrm{Q}_{10}$ method predicted up to 66 days and 64 days of shelf-life at room-temperature, respectively.

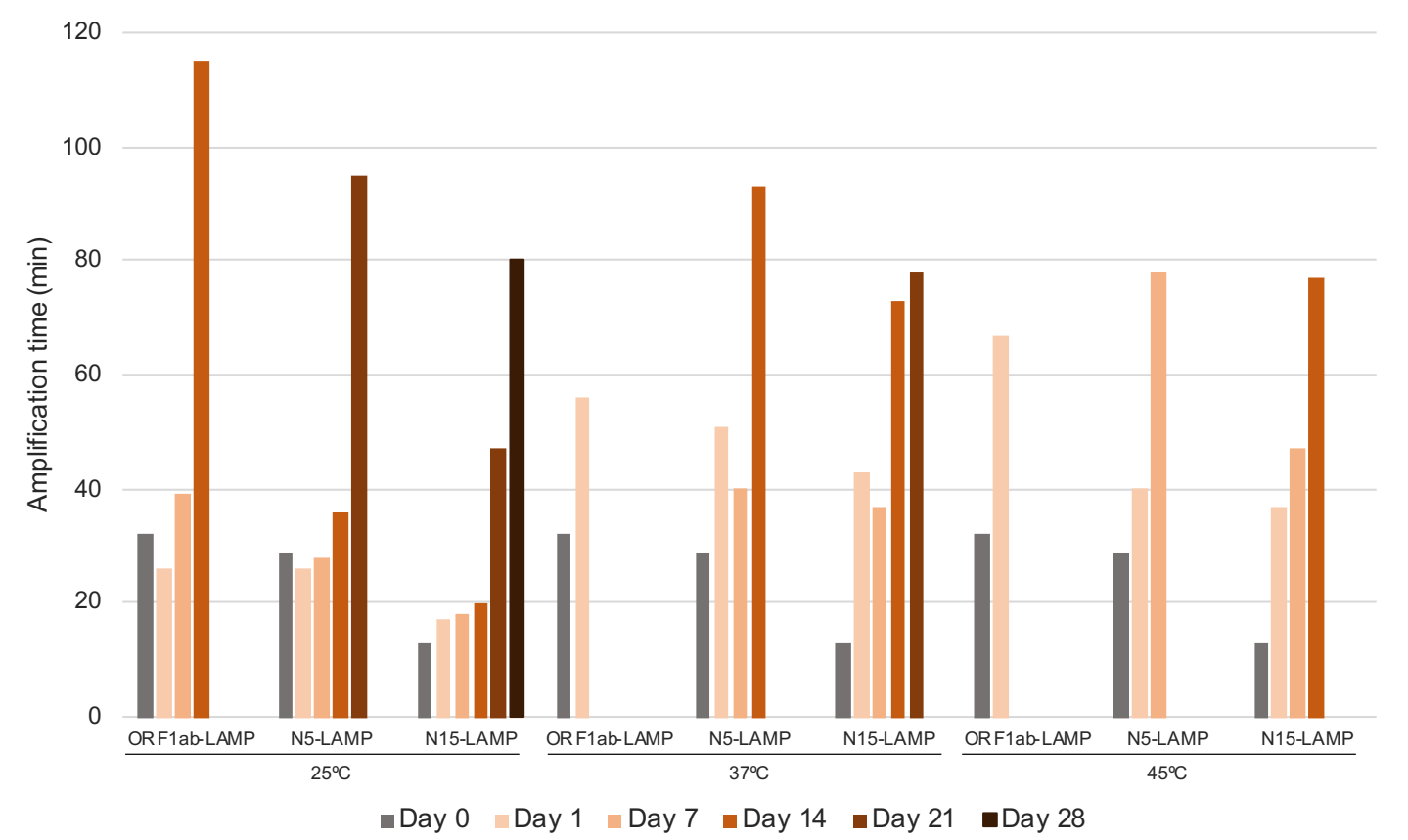

Figure 6. Amplification time of Dry-RT-LAMP assays as a function of storage time and temperature. Amplification times of $\mathrm{C}+$ in RT-LAMP assays performed with dryreagents including primer sets ORF1ab, N5 and N15 tested at 0,1, 7, 14, 21 and 28-days post-desiccation is shown. The different storage temperature $\left(25^{\circ} \mathrm{C}, 37^{\circ} \mathrm{C}\right.$ and $\left.45^{\circ} \mathrm{C}\right)$ is also indicated.

Dry-N15-RT-LAMP assay was also tested at 0, 1 and 7-days post-desiccation with the same samples used in colorimetric RT-LAMP assays (nos. 4, 5, 6, 7, 12, 14, 15, and 16). Results obtained are shown in Figure 7. As for $\mathrm{C}+$ amplification trials, an increase in the threshold time values was observed in comparison to fresh reactions. The only sample with no amplification at any post-desiccation time was the no. 12, which presented the highest $\mathrm{Ct}$ values in RT-qPCR for both ORF1b $(\mathrm{Ct}=39 \mathrm{~min})$ and $\mathrm{N}(\mathrm{Ct}=36 \mathrm{~min})$. The 
sample no. 14 (with a high $\mathrm{Ct}=33$ min for ORF1ab and E- by RT-qPCR) was amplified with high $\mathrm{Ct}$ values at $0(\mathrm{Ct}=81 \mathrm{~min}), 1(\mathrm{Ct}=85 \mathrm{~min})$ and $7(\mathrm{Ct}=75 \mathrm{~min})$ days postdesiccation; interestingly, a high $\mathrm{Ct}=47 \mathrm{~min}$ was also obtained with N15-RT-LAMP fresh mixture. The samples nos. 15 and 16 (with no amplification of ORF1ab and N+ by RTqPCR) amplified with high $\mathrm{Ct}$ values at 0 and 1 day post-desiccation, respectively. These samples also presented a relatively high $\mathrm{Ct}$ values in fresh N15-RT-LAMP. The samples nos. 4, 5, 6 (group 1; $\mathrm{Ct} \leq 30 \mathrm{~min}$ ) and 7 (group 2; $\mathrm{Ct}>30 \mathrm{~min}$ ) were all amplified at 0,1 and 7-days post-desiccation with very reasonable $\mathrm{Ct}$ values in comparison to fresh mixtures.

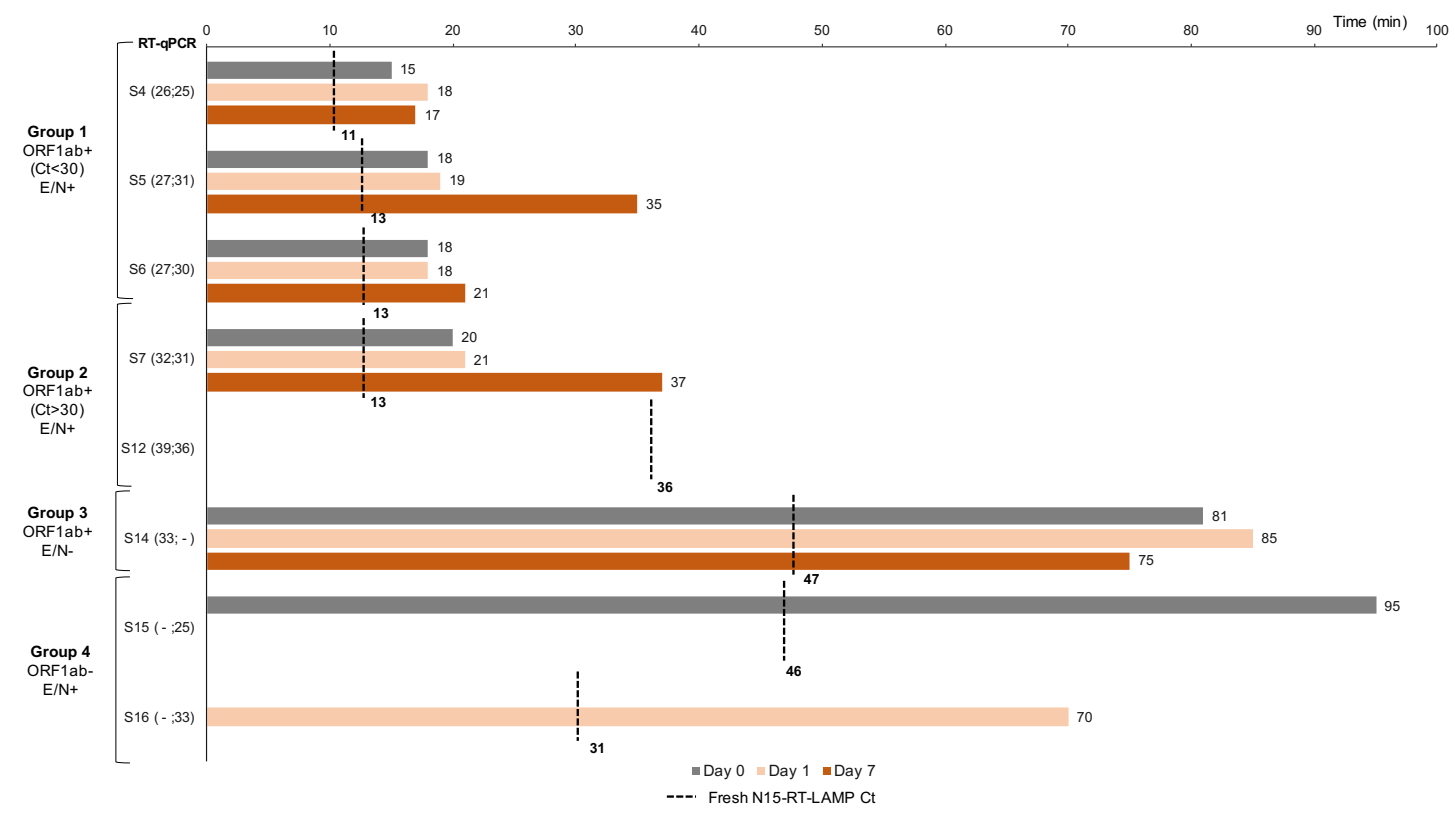

Fig. 7. Dry-RT-LAMP assessment using primers set N15 in RNA isolates from COVID-19 patients. Amplification times of samples nos. 4, 5, 6, 7, 12, 14, 15 and 16, performed with dry reagents including primer set N15 at 0, 1, and 7-days post-desiccation are shown. As reference for comparison, discontinuous black lines indicate amplification times obtained in N15-RT-LAMP assays using fresh liquid mixes.

\section{DISCUSSION}

In this work, five regions from SARS-CoV-2 viral genome were studied, including the open reading frames ORF1a and ORF1b, and genes $\mathrm{S}, \mathrm{E}$ and $\mathrm{N}$ and eight sequencespecific RT-LAMP primer sets were finally designed and screened for the detection of the novel coronavirus. Our RT-LAMP reaction was optimized using a well-established RNA-positive control from a COVID-19 patient and primer sets targeting ORF1ab, gene $\mathrm{E}$, and gene $\mathrm{N}$ were finally selected. For most RT-LAMP assays detecting SARS-CoV- 
2, the genes ORF $1 \mathrm{ab}$ and $\mathrm{N}$ have been used as the principal targets for amplification ${ }^{33}$. In fact, in our trials, we obtained the best performance in detecting SARS-CoV-2 RNA targeting these two genes, not only in threshold values, but also in analytical sensitivity. Firstly, we established the proper operation of the primer sets designed, specificity and sensitivity in the amplification of the selected SARS-CoV-2 RNA target sequences. In set-up trials, the RT-LAMP reactions using Bst 3.0 DNA polymerase did not work well and, frequently, nonspecific amplification was observed. It has been previously described a number of differences in efficiency of Bst 3.0 compared to Bst 2.0 WS depending on time and temperature for amplification ${ }^{38}$. As Bst 3.0 has an optimal temperature range for amplification between $68^{\circ} \mathrm{C}-70^{\circ} \mathrm{C}$, it is possible that when testing different temperatures in the optimization of RT-LAMP, a suboptimal annealing of our primer sets occurred, thus probably increasing the irregular and nonspecific amplification. In addition, it has been recently described a significantly increased tendency of Bst 3.0 to yield false positive results in comparison to Bst 2.0. These unspecific products were characterized by a higher Tm than specific products which also occurred in our Bst 3.0 reactions. These false positives have been associated with the interaction of multiple primers and the template switching and terminal transferase activities of the polymerase, combined with a lack of $3^{\prime} \rightarrow 5^{\prime}$ exonuclease activity ${ }^{39}$. In this sense, although some previously reported RT-LAMP tests for diagnosis of COVID-19 appear to have worked well using Bst 3.0 $0^{40,41}$, different primers sequences targeting gene $\mathrm{N}$ were used and then annealing could be probably more effective or be less constrained by primer interaction. Nevertheless, most studies use a combination of a Bst 2.0 WS DNA polymerase and RTx WS in one-step reaction to amplify gene ORF1ab or gene $\mathrm{N}^{33}$. In our trials, optimization of RT-LAMP was finally carried out using the combination of the two enzymes and the best performance resulted for the amplification of regions ORF1ab, E, and N (using both primer sets N5 and N15). The lowest $\mathrm{Ct}$ values for RT-LAMP assays were obtained targeting gene N, particularly with primer set $\mathrm{N} 15(\mathrm{Ct}=15 \mathrm{~min})$.

Regarding specificity, RT-LAMP showed to be highly specific for SARS-CoV-2 since no cross-reaction resulted in silico comparisons and nor when RNA isolates from other human respiratory virus were evaluated. As may occur with any molecular-based test, possible mutations can arise in viral sequences and may affect primer annealing, thus causing a failure in further amplifications. To date, of the mutations reported for SARS$\mathrm{CoV}-2^{42}$, none of them match in the sequences targeted by the primer sets used in RTLAMP assays. In addition, it seems that mutations (most of them single-nucleotide 
alterations between viruses from different people) makes SARS-CoV-2 change much more slowly as it spreads ${ }^{43}$.

RT-LAMP reactions targeting ORF1ab and N (using sets N5 and N15) demonstrated a limit of detection of 200 copies of SARS-CoV-2 RNA/reaction. The sensitivity of amplification based on gene $\mathrm{E}$ detection was proved to be lower (2,000 copies/reaction) than ORF1ab or N genes. This might be caused by the slower kinetics of the RT-LAMP reaction targeting gen $\mathrm{E}$, which lacks in loop primers, and therefore does not allow to detect low concentrations of viral RNA within a reasonable time. Besides, most of the RT-LAMP assays developed to date do target genes ORF1ab or $\mathrm{N}^{33}$, and do not gene $\mathrm{E}$, thus suggesting poorer results when using this target. Other published studies have reported sensitivities as low as 2 copies/reaction for both ORF1ab and $\mathrm{N}$ genes $^{28}$ or 3 copies/reaction for gene ORF $1 \mathrm{ab}^{20}$. However, those results for analytical sensitivity in detecting SARS-CoV-2 RNA were found using synthesized RNA fragments of genes N and ORF1ab obtained from in vitro transcription instead real RNA isolates from COVID19 patients. Our results are in line with those larger clinical studies in which RT-LAMP assays present analytical sensitivities around hundreds of copies of SARS-CoV-2 genomic RNA ${ }^{17,25,44}$.

A great variability in viral load in COVID-19 patients has been reported, ranging from 641 copies $/ \mathrm{mL}$ to $1.34 \times 10^{11}$ copies $/ \mathrm{mL}$ (with a median of $7.99 \times 10^{4}$ in throat samples and $7.52 \times 10^{5}$ in sputum samples) and $1.69 \times 10^{5}$ copies $/ \mathrm{mL}$ in a nasal swab sample ${ }^{45}$. Other studies testing SARS-CoV-2 positive patients estimated a viral load ranging from 1 copy $/ \mu \mathrm{L}$ to $10^{8}$ copies $/ \mu \mathrm{L}$, with most samples ranging from $10^{4}-10^{8}$ copies $/ \mu \mathrm{L}^{46}$ or median viral load of 1,440 copies/ $\mu \mathrm{L}$ in nasopharyngeal swab samples ${ }^{47}$. In addition, a study performed by $\mathrm{Yu}$ et al $^{48}$ showed that the viral loads in the early and progressive stages were significantly higher (over 46,000 copies) than in the recovery stage of the disease (over 1,200 copies). Despite these variations in viral load of COVID-19 patients, our RTLAMP assay resulted sensitive enough for detection of SARS-CoV-2 RNA in clinical samples, as it seems to indicate the comparison of $\mathrm{Ct}$ values with those obtained with RTqPCR. Thus, for samples with a $\mathrm{Ct} \leq 30$ obtained by RT-qPCR (group 1), we found an excellent sensitivity and specificity values for viral RNA by RT-LAMP assays using primer sets ORF1ab, N5 and N15. The Ct values for the three RT-LAMP assays resulted much lower than those obtained with RT-qPCR. This fact is even more significant if we take into account that to calculate the Ct of the RT-LAMP assay, both the time dedicated to retro-transcription and amplification are considered, while the Ct of the RT-qPCR does 
not include the time dedicated to retro-transcription. In general, for clinical samples with Ct>30 (or with only one RT-qPCR-amplified target; suggestive positives), RT-LAMP assays were initially less sensitive, and amplification was not obtained in all samples. However, the RT-LAMP with the primers set N15, although with high threshold time values, tested positive in all but one sample, probably suggesting a sensitivity significantly lower than 200 copies/reaction for N15-RT-LAMP.

In all, in this work we have developed three highly efficient RT-LAMP assays for the detection of SARS-CoV-2 RNA. Considering those samples with a RT-qPCR-positive result for two different targets (nos. 1-12; confirmed positives), value of sensitivities resulted in 75\% (9/12) for N5-RT-LAMP, 83.3\% (10/12) for ORF1ab-RT-LAMP, and 100\% (12/12) for N15-RT-LAMP. Furthermore, if we consider only samples nos. 1-10, with a RT-qPCR $\mathrm{Ct} \leq 33$ for ORF1ab (equivalent to approximately 10-100 copies), sensitivities of ORF1ab-RT-LAMP and N5-RT-LAMP increase to $100 \%$ and $90 \%$, respectively. It should be also noted that $\mathrm{Ct}$ values for N5-RT-LAMP were considerably lower than the Ct values for RT-qPCR targeting gene $\mathrm{N}$ (nos. 1, 3, 4, 5, 6, 7, and 9), and all positive result could be detected with excellent reaction times under $25 \mathrm{~min}$. All these results suggest that any of the three RT-LAMP assays would be able to detect COVID19 patients in all disease stages (early, progressive and recovery) according to the currently known data on viral load of SARS-CoV-2 in clinical samples ${ }^{45-48}$. The significant correlation between RT-qPCR and RT-LAMP threshold times obtained particularly in theoretically high viral load samples $(\mathrm{Ct} \leq 30)$ - together with the absolute agreement between real-time and conventional colorimetric RT-LAMP assays, increase the confidence in our results. Nevertheless, the increased variability in Ct values that N15RT-LAMP presented with theoretically low viral load samples $(\mathrm{Ct}>30)$ cannot be disregarded. In this respect, it is important to note that a lack of correlation between speed and sensitivity in isothermal amplification reactions has been previously reported ${ }^{49}$ and reactions with higher efficiency can have substantially longer times to be positive, thus contradicting the intuition derived from $\mathrm{qPCR}$ reactions. We are aware of the limitations of our study in terms of the sample size and we acknowledge that further studies to examine the reproducibility of N15-RT-LAMP in testing larger sets of clinical samples are needed.

In an effort to develop a RT-LAMP as simple as possible to carry out in any condition for SARS-CoV-2 detection, we tried to keep all necessary components in a non-reactive state using tubes containing dry master mixes coated on the inner walls and caps. In a 
previous work, we successfully developed a simple desiccation procedure for drying LAMP reagents adapted for conventional and real-time amplifications assays ${ }^{14}$. Now, for COVID-19 RT-LAMP test, that protocol has been modified to achieve better thermal stability of dehydrated RT-LAMP mixes at ambient temperature along time. A Dry-RTLAMP format can overcomes the requirement of cold storage facilities and temperaturecontrolled shipping ${ }^{50,51}$, allows to omit adding reagents individually, making the process easier and faster, and avoids possible cross-contamination during multiple pipetting steps in master mix preparation. The new 30 min one-step dry-up protocol was applied for RTLAMP mixes containing primer sets ORF1ab, N5 and N15, resulting in functional amplifications of the $\mathrm{C}+$ after storage at $\mathrm{RT}\left(25^{\circ} \mathrm{C}\right)$ for up 14, 21 and 28 days, respectively. At this moment, we are not aware of the underlying cause of differences in stability when using different primer sets, but it could be possible than the higher efficiency showed by RT-LAMP with the primers set N15 allowed to amplify viral RNA after longer periods of storage. On the other hand, the longer dry components are storage at RT, the longer the reaction incubation time to achieve amplification is needed. An increase in reaction time, as well as a reduction in the amplification level in comparison to fresh liquid mixtures was already described by our group in operation of desiccation LAMP procedure $^{14}$. In any case, very reasonable amplification times of $80 \mathrm{~min}$ (for set N15), 95 min (for set N5) and $115 \mathrm{~min}$ (for set ORF1ab) were observed before functionality loss after storage for 28, 21 or 14 days, respectively. Additionally, the $\mathrm{Q}_{10}$ method predicts a shelf-life for Dry-RT-LAMP using primer set N15 of over 64-66 days at $25^{\circ} \mathrm{C}$. Subsequently, the Dry-N15-RT-LAMP format was selected to test those eight samples used in conventional colorimetric RT-LAMP assay at 0 , 1 , and 7 days post-desiccation. In analysis, an expected increase in the $\mathrm{Ct}$ values was observed in comparison to results obtained in N15-RT-LAMP fresh liquid reactions. Thus, those samples with high $\mathrm{Ct}$ values when testing in fresh using primer set N15 (presumably with a very low viral load or marginal positives: nos. 12, 14, 15 and 16) did not work very well at post-desiccation times, resulting in no amplification or in amplification with $\mathrm{Ct}$ values much more higher. By contrast, those samples with low $\mathrm{Ct}$ values in fresh testing (presumably with medium/high viral load: nos. 4, 5, 6 and 7), despite increase slightly in reaction time, were consistently detected over post-desiccation time.

In summary, we have developed a novel, rapid, specific and sensitive RT-LAMP test for SARS-CoV-2 RNA detection in clinical samples by targeting gene $\mathrm{N}$ with a specificsequence primer set N15. Our RT-LAMP assay can be simply performed both as a single- 
tube isothermal colorimetric method without any expensive equipment requirement and in a real-time platform. The results can be detected as soon as 9 min after the reaction starts and obtain close to $100 \%$ sensitivity within $60 \mathrm{~min}$. Moreover, the procedure is easily adaptable to a dry-format that could be stored and delivered at room temperature. At this moment, maintaining the functionality for at least 2 months at RT, would allow us to prepare and distribute a set of dried RT-LAMP master mixes to be used within a few weeks in settings where detection of SARS-CoV-2 is required at the point of collection, such as schools, nursing homes or rural medical centers. Furthermore, the possibility of avoid the RNA extraction, or the combination of this RT-LAMP with some rapid RNA purification methods already described ${ }^{22,34,52}$, could allow easy testing in situations of rapid diagnostic demand and in low-resource settings and areas of difficult access, where the limited testing capacity is one of the main challenges in the COVID-19 response $^{53}$. We are currently working on this with the aim to improve and achieve a POC molecular diagnosis of COVID-19.

\section{AKNOWLEGMENTS}

This research was funded by the Consejería de Educación de la Junta de Castilla y León (COV20EDU/00657). European Union cofinancing by FEDER (Fondo Europeo de Desarrollo Regional) 'Una manera de hacer Europa'. We also acknowledge support by the Predoctoral Fellowship Program of University of Salamanca and cofinancing by Santander Bank.

\section{REFERENCES}

1. Zhu, N. et al. A novel coronavirus from patients with pneumonia in China, 2019. N. Engl. J. Med. 382, 727-733 (2020).

2. Dhama, K. et al. Coronavirus Disease 2019-COVID-19. Clin. Microbiol. Rev. 33, e00028-20 (2020).

3. Backer, J. A., Klinkenberg, D. \& Wallinga, J. Incubation period of 2019 novel coronavirus (2019- nCoV) infections among travellers from Wuhan, China, 2028 January 2020. Eurosurveillance 25, 1-6 (2020).

4. Oran, D. P. \& Topol, E. J. Prevalence of Asymptomatic SARS-CoV-2 Infection : A Narrative Review. Ann. Intern. Med. 173, 362-367 (2020). 
5. Huang, C. et al. Clinical features of patients infected with 2019 novel coronavirus in Wuhan, China. Lancet 395, 497-506 (2020).

6. Baj, J. et al. COVID-19: Specific and Non-Specific Clinical Manifestations and Symptoms: The Current State of Knowledge. J. Clin. Med. 9, 1753 (2020).

7. Liu, K. et al. Clinical characteristics of novel coronavirus cases in tertiary hospitals in Hubei Province. Chin. Med. J. (Engl). 133, 1025-1031 (2020).

8. Shen, M. et al. Recent advances and perspectives of nucleic acid detection for coronavirus. J. Pharm. Anal. 10, 97-101 (2020).

9. Carter, L. J. et al. Assay Techniques and Test Development for COVID-19 Diagnosis. ACS Cent. Sci. 6, 591-605 (2020).

10. Esbin, M. N. et al. Overcoming the bottleneck to widespread testing: A rapid review of nucleic acid testing approaches for COVID-19 detection. Rna 26, 771$783(2020)$.

11. Loeffelholz, M. J. \& Tang, Y. W. Laboratory diagnosis of emerging human coronavirus infections-the state of the art. Emerg. Microbes Infect. 9, 747-756 (2020).

12. Notomi, T. et al. Loop-mediated isothermal amplification of DNA. Nucleic Acids Res. 28, e63 (2000).

13. Notomi, T., Mori, Y., Tomita, N. \& Kanda, H. Loop-mediated isothermal amplification (LAMP): principle, features, and future prospects. J. Microbiol. 53, $1-5(2015)$

14. García-Bernalt Diego, J. et al. Progress in loop-mediated isothermal amplification assay for detection of Schistosoma mansoni DNA: towards a readyto-use test. Sci. Rep. 9, 14744 (2019).

15. Wong, Y. P., Othman, S., Lau, Y. L., Radu, S. \& Chee, H. Y. Loop-mediated isothermal amplification (LAMP): a versatile technique for detection of microorganisms. J. Appl. Microbiol. 124, 626-643 (2018).

16. Augustine, R. et al. Loop-mediated isothermal amplification (Lamp): A rapid, sensitive, specific, and cost-effective point-of-care test for coronaviruses in the context of covid-19 pandemic. Biology (Basel). 9, 1-17 (2020).

17. Yan, C. et al. Rapid and visual detection of 2019 novel coronavirus (SARS-CoV2) by a reverse transcription loop-mediated isothermal amplification assay. Clin. Microbiol. Infect. 26, 773-779 (2020).

18. Lamb, L. E., Bartolone, S. N., Ward, E. \& Chancellor, M. B. Rapid detection of 
novel coronavirus/Severe Acute Respiratory Syndrome Coronavirus 2 (SARSCoV-2) by reverse transcription-loop-mediated isothermal amplification. PLoS One 15, e0234682 (2020).

19. Park, G. S. et al. Development of Reverse Transcription Loop-Mediated Isothermal Amplification Assays Targeting Severe Acute Respiratory Syndrome Coronavirus 2 (SARS-CoV-2). J. Mol. Diagnostics 22, 729-735 (2020).

20. Lu, R. et al. Development of a Novel Reverse Transcription Loop-Mediated Isothermal Amplification Method for Rapid Detection of SARS-CoV-2. Virol. Sin. 12250, (2020).

21. Huang, W. E. et al. RT-LAMP for rapid diagnosis of coronavirus SARS-CoV-2. Microb. Biotechnol. 13, 950-961 (2020).

22. Lalli, M. A. et al. Rapid and extraction-free detection of SARS-CoV-2 from saliva with colorimetric LAMP. medRxiv (2020).

23. Yu, L. et al. Rapid Detection of COVID-19 Coronavirus Using a Reverse Transcriptional Loop-Mediated Isothermal Amplification (RT-LAMP) Diagnostic Platform. Clin. Chem. 66, 975-977 (2020).

24. El-Tholoth, M., Bau, H. H. \& Song, J. A Single and Two-Stage, Closed-Tube, Molecular Test for the 2019 Novel Coronavirus (COVID-19) at Home, Clinic, and Points of Entry. ChemRxiv (2020).

25. Baek, Y. H. et al. Development of a reverse transcription-loop-mediated isothermal amplification as a rapid early-detection method for novel SARS-CoV2. Emerg. Microbes Infect. 9, 998-1007 (2020).

26. Lu, R. et al. A novel reverse transcription loop-mediated isothermal amplification method for rapid detection of sars-cov-2. Int. J. Mol. Sci. 21, (2020).

27. Lau, Y. L. et al. Real-time reverse transcription loop-mediated isothermal amplification for rapid detection of SARS-CoV-2. PeerJ 8, e9278 (2020).

28. Huang, J. \& Zhao, L. A high-throughput strategy for COVID-19 testing based on next-generation sequencing. medRxiv (2020).

29. Butler, D. J. et al. Host, Viral, and Environmental Transcriptome Profiles of the Severe Acute Respiratory Syndrome Coronavirus 2 (SARS-CoV-2). bioRxiv (2020).

30. Broughton, J. P. et al. CRISPR-Cas12-based detection of SARS-CoV-2. Nat. Biotechnol. 38, 870-874 (2020).

31. Centers for Disease Control and Prevention. Real-Time RT-PCR Diagnostic 
Panel For Emergency Use Only. 4, (2020).

32. Rödel, J. et al. Use of the variplex ${ }^{\mathrm{TM}}$ SARS-CoV-2 RT-LAMP as a rapid molecular assay to complement RT-PCR for COVID-19 diagnosis. J. Clin. Virol. 132, $104616(2020)$.

33. Thompson, D. \& Lei, Y. Mini review: Recent progress in RT-LAMP enabled COVID-19 detection. Sensors and Actuators Reports 2, 100017 (2020).

34. Rabe, B. A. \& Cepko, C. SARS-CoV-2 detection using isothermal amplification and a rapid, inexpensive protocol for sample inactivation and purification. Proc. Natl. Acad. Sci. 117, 24450-24458 (2020).

35. Wu, F. et al. A new coronavirus associated with human respiratory disease in China. Nature 579, 265-269 (2020).

36. Clark, G. S. Shelf Life of Medical Devices. FDA's Good Guid. Pract. GGP's. 27 (1991).

37. Reyes, B. A., Pendergast, J. S. \& Yamazaki, S. Mammalian peripheral circadian oscillators are temperature compensated. J. Biol. Rhythms 23, 95-98 (2008).

38. Rolando, J. C., Jue, E., Schoepp, N. G. \& Ismagilov, R. F. Real-Time, Digital LAMP with Commercial Microfluidic Chips Reveals the Interplay of Efficiency, Speed, and Background Amplification as a Function of Reaction Temperature and Time. Anal. Chem. 91, 1034-1042 (2019).

39. Rolando, J. C., Jue, E. \& Barlow, J. T. Real-time kinetics and high-resolution melt curves in single-molecule digital LAMP to differentiate and study specific and non-specific amplification. Nucleic Acids Res. 1-21 (2020).

40. Wang, D. One-pot Detection of COVID-19 with Real-time Reverse-transcription Loop-mediated Isothermal Amplification (RT-LAMP) Assay and Visual RTLAMP Assay. bioRxiv (2020).

41. Schmid-Burgk, J. L. et al. LAMP-Seq: Population-Scale COVID-19 Diagnostics Using a Compressed Barcode Space. bioRxiv (2020).

42. Khailany, R. A., Safdar, M. \& Ozaslan, M. Genomic characterization of a novel SARS-CoV-2 Rozhgar. Gene Reports 19, 1-6 (2020).

43. Callaway, B. E. Making sense of Coronavirus mutations. Nature 585, 174-177 (2020).

44. Jiang, M. et al. Development and Validation of a Rapid, Single-Step Reverse Transcriptase Loop-Mediated Isothermal Amplification (RT-LAMP) System Potentially to Be Used for Reliable and High-Throughput Screening of COVID- 
19. Front. Cell. Infect. Microbiol. 10, 1-6 (2020).

45. Pan, Y., Zhang, D., Yang, P., Poon, L. L. M. \& Wang, Q. Viral load of SARSCoV-2 in clinical samples. Lancet Infect. Dis. 20, 411-412 (2020).

46. Corman, V. M. et al. An analysis of SARS-CoV-2 viral load by patient age. medRxiv (2020).

47. Pujadas, E. et al. Comparison of SARS-CoV-2 detection from nasopharyngeal swab samples by the Roche cobas 6800 SARS-CoV-2 test and a laboratorydeveloped real-time RT-PCR test. J. Med. Virol. 92, 1695-1698 (2020).

48. Yu, F. et al. Quantitative Detection and Viral Load Analysis of SARS-CoV-2 in Infected Patients. Clin. Infect. Dis. 71, 793-798 (2020).

49. Khorosheva, E. M., Karymov, M. A., Selck, D. A. \& Ismagilov, R. F. Lack of correlation between reaction speed and analytical sensitivity in isothermal amplification reveals the value of digital methods for optimization: Validation using digital real-time RT-LAMP. Nucleic Acids Res. 44, e10 (2016).

50. Hayashida, K., Kajino, K., Hachaambwa, L., Namangala, B. \& Sugimoto, C. Direct Blood Dry LAMP: A Rapid, Stable, and Easy Diagnostic Tool for Human African Trypanosomiasis. PLoS Negl. Trop. Dis. 9, 1-14 (2015).

51. Chander, Y. et al. A novel thermostable polymerase for RNA and DNA loopmediated isothermal amplification (LAMP). Front. Microbiol. 5, 1-11 (2014).

52. Klein, S. et al. SARS-CoV-2 RNA Extraction Using Magnetic Beads for Rapid Large-Scale Testing by RT-qPCR and RT-LAMP. Viruses 12, 863 (2020).

53. Margolin, E. et al. Prospects for SARS-CoV-2 diagnostics, therapeutics and vaccines in Africa. Nat. Rev. Microbiol. (2020). 


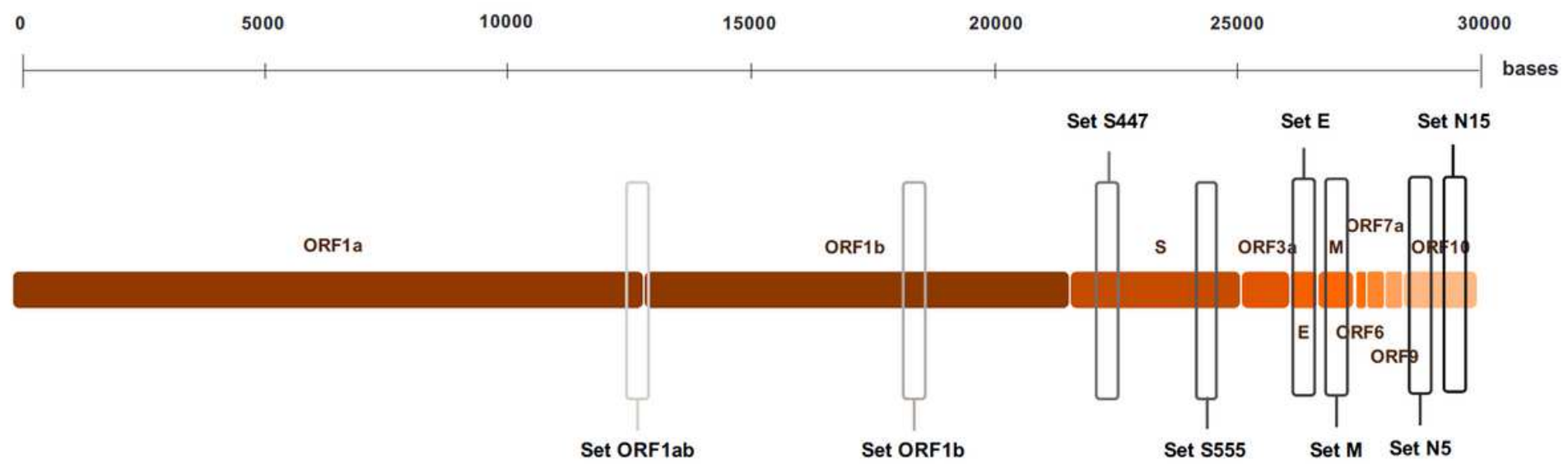

\section{Figure 1}

Schematic representation of COVID-LAMP target localization within SARS-CoV-2 genome. Genbank sequence accession number: MN908947.335

\section{ORF1ab}
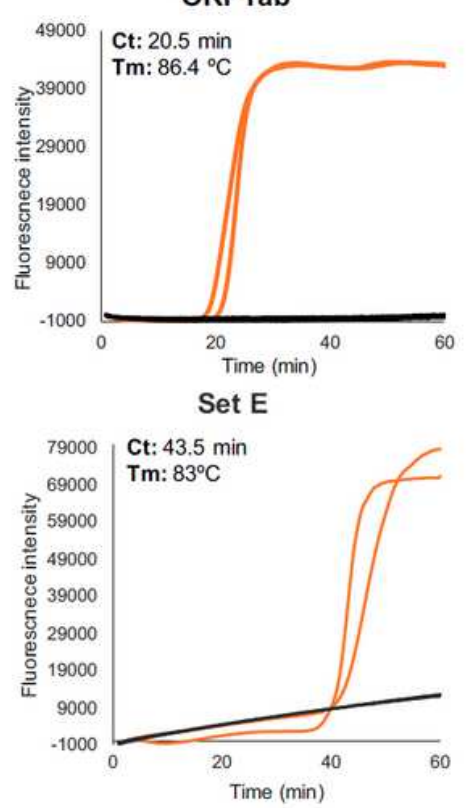

Set ORF1b
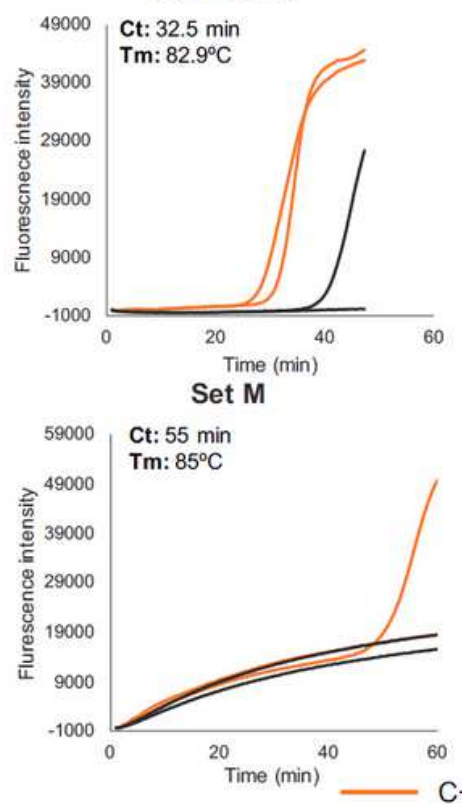

Set S447
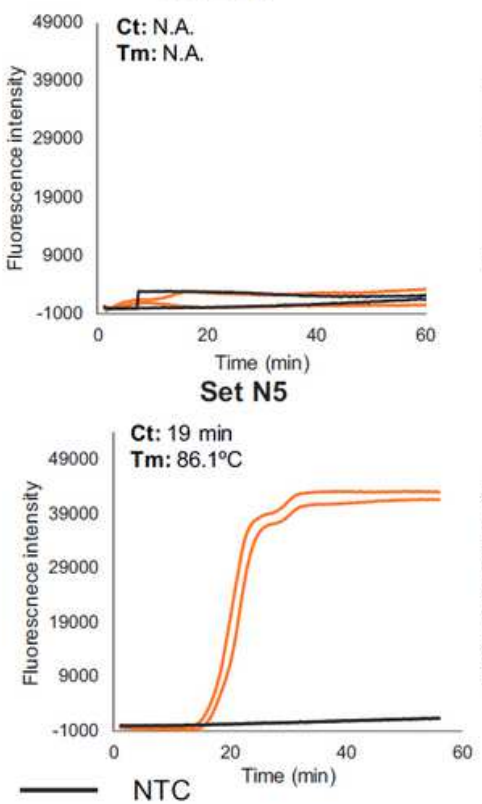

Set S555
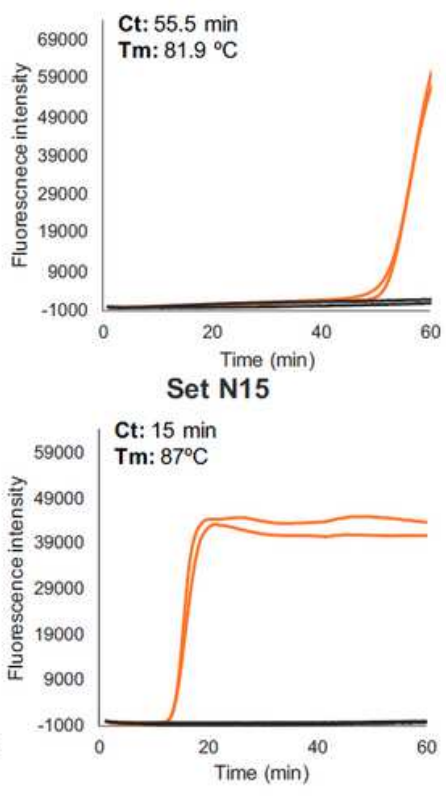

\section{Figure 2}

Real-time RT-LAMP assays performed using the eight primers sets evaluated for the detection of SARSCoV-2. EvaGreen 20x fluorescence signal over time for primer sets ORF1ab, ORF1b, S447, S555, E, M, N5, and $\mathrm{N} 15$ is shown. Orange lines (C+, positive control); black lines (NTC, non-template control). Threshold values $(\mathrm{Ct} ; \mathrm{min})$ and melting temperatures $\left(\mathrm{Tm} ;{ }^{\circ} \mathrm{C}\right)$ for each primer set are indicated. All reactions were performed in duplicates. 

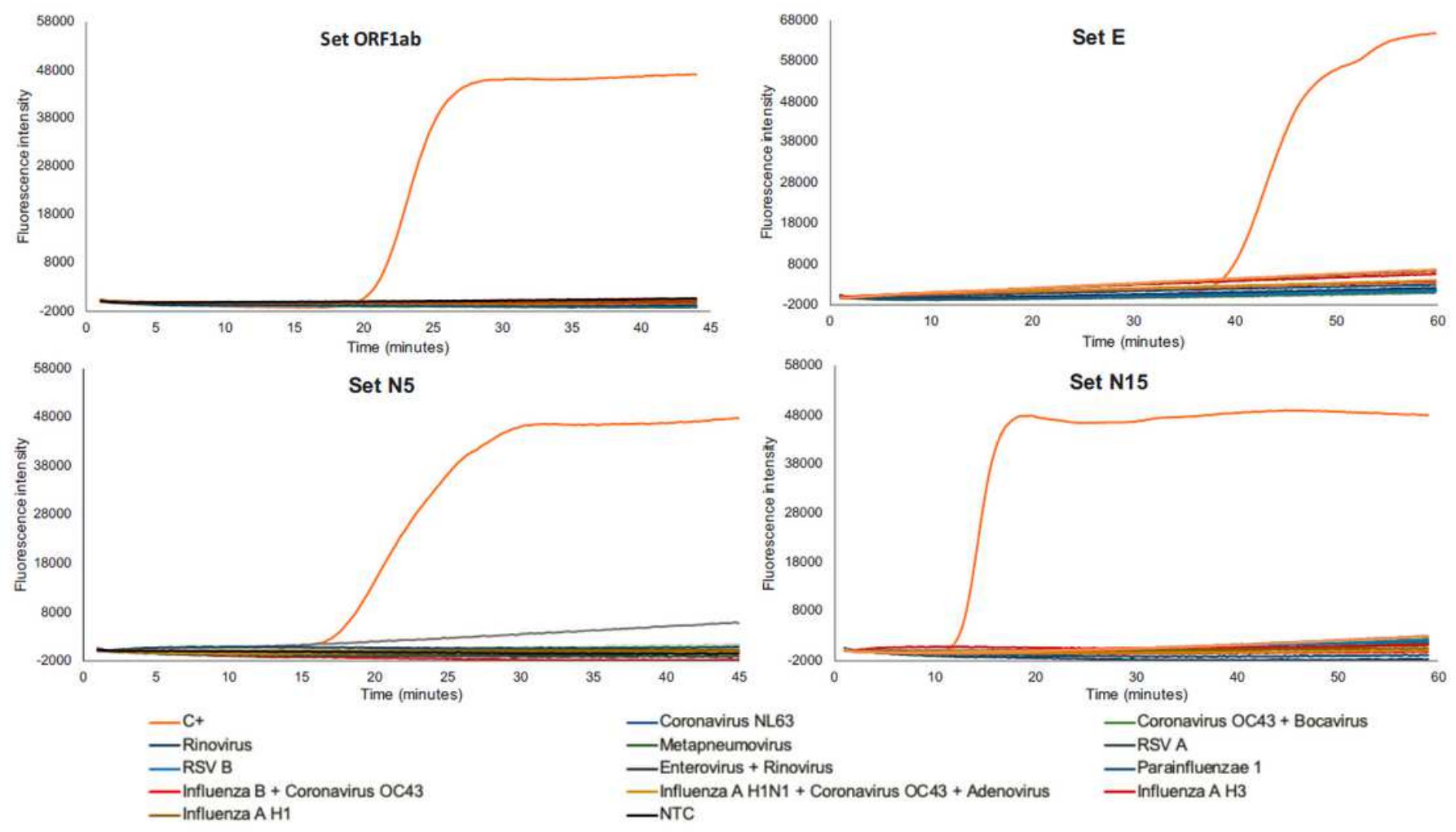

- Coronavirus $\mathrm{OC} 43+$ Bocavirus

- RSV A

- Parainfluenzae 1

- Influenza A H3

\section{Figure 3}

Specificity assessment of the RT-LAMP assays for SARS-CoV-2 RNA detection using primer sets ORF1ab, E, N5 and N15. A panel of 13 purified RNA isolates of related virus obtained from infected patients are included: Coronavirus NL63, Coronavirus OC43, Bocavirus, Rinovirus, Metapneumovirus, Respiratory Syncytial Virus A, Respiratory Syncytial Virus B, Enterovirus, Parainfluenzae 1, Influenza H1N1, Influenza A H3, Influenza A H1, and Influenza B. One sample contained RNA from two virus (Influenza B + Coronavirus OC43); other sample contained RNA from three virus (Influenza A H1 + Coronavirus OC43 + Adenovirus). 
Set ORF1ab

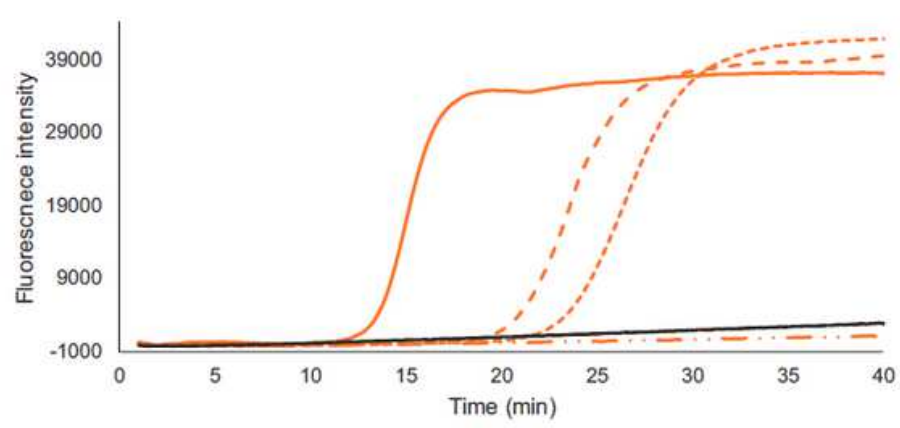

Set N5

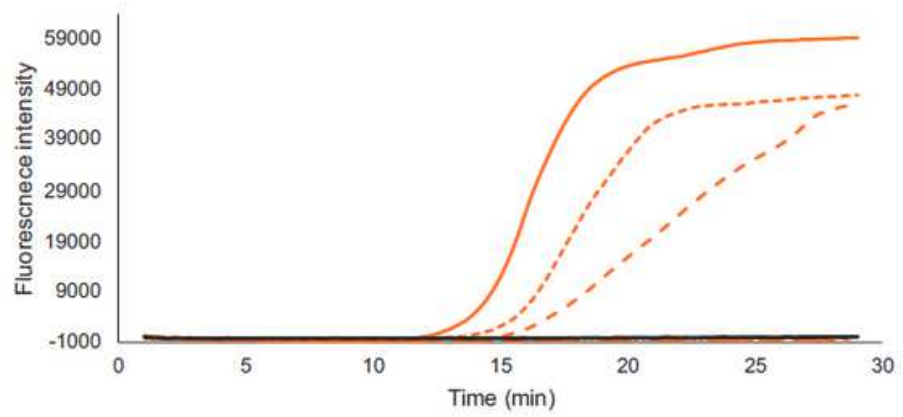

Set E

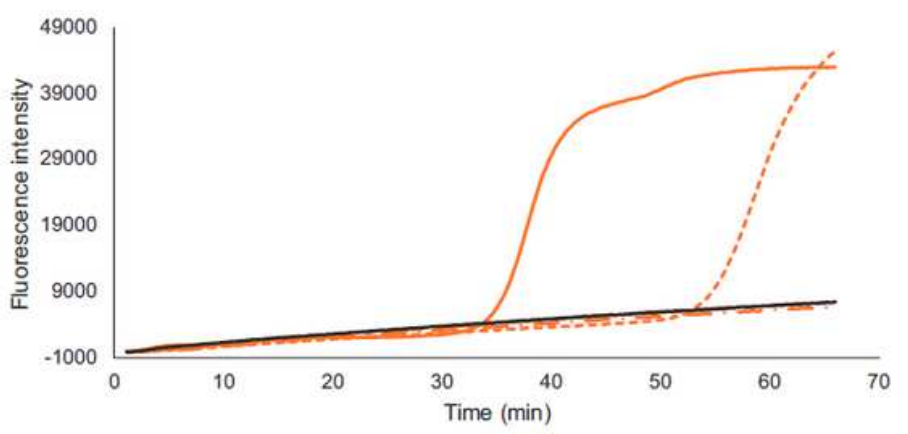

Set N15

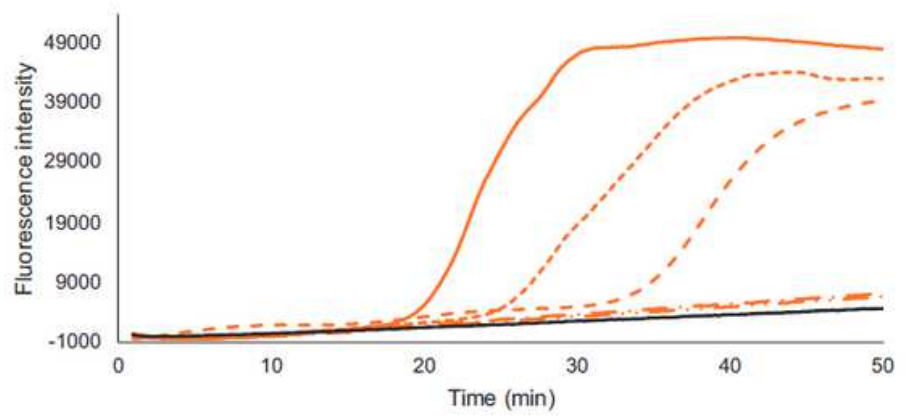

NTC

\section{Figure 4}

Sensitivity assessment of the RT-LAMP assays for SARS-CoV-2 RNA detection using primer sets ORF1ab, E, N5 and N15. The 10-fold dilutions (1x-1:104) of positive control $(\mathrm{C}+)$ are represented by orange lines; non-template control (NTC) is represented by black lines. 


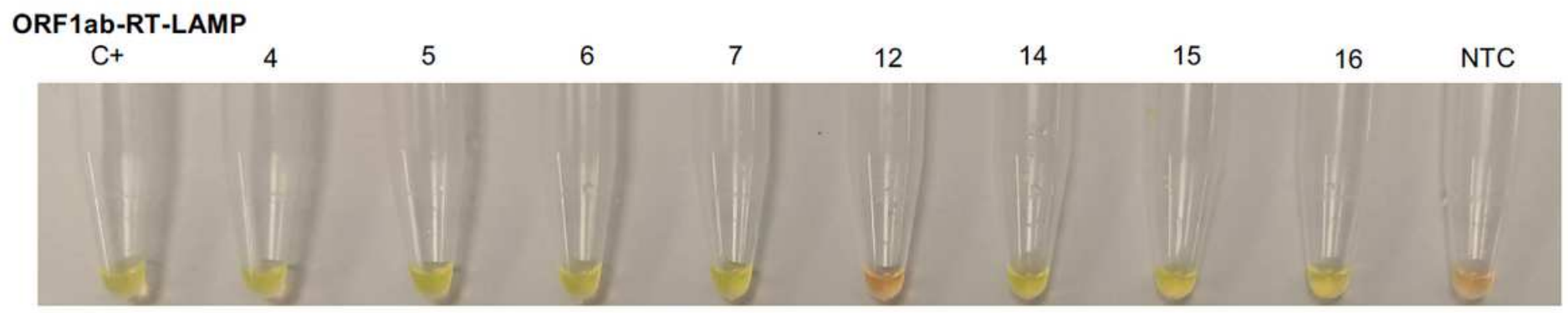

N5-RT-LAMP

\begin{tabular}{|l|l|l|l|l|l|l|l|}
$\mathrm{C}+$ & 5 & 6 & 7 & 12 & 14 & 15 & NTC \\
\hline
\end{tabular}

\section{N15-RT-LAMP}

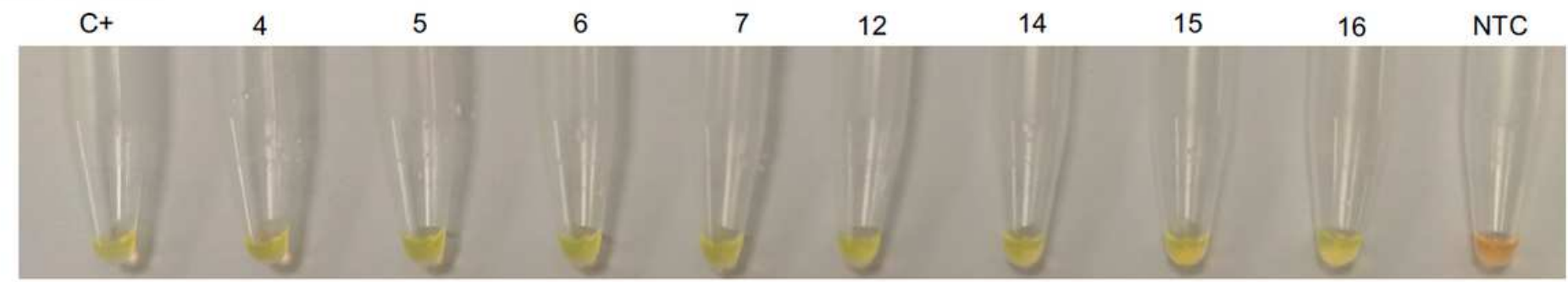

\section{Figure 5}

Conventional colorimetric RT-LAMP assays using the primer sets ORF1ab, N5, and N15. Eight RNA isolates from COVID-19 patients (samples nos. 4, 5, 6, 7, 12, 14, 15, and 16) were analyzed by colorimetric RT-LAMP using SYBR ${ }^{\circledR}$ Green fluorescent dye. Green (positive samples), orange (negative samples). C+, RNA-positive control; NTC, non-template control. 


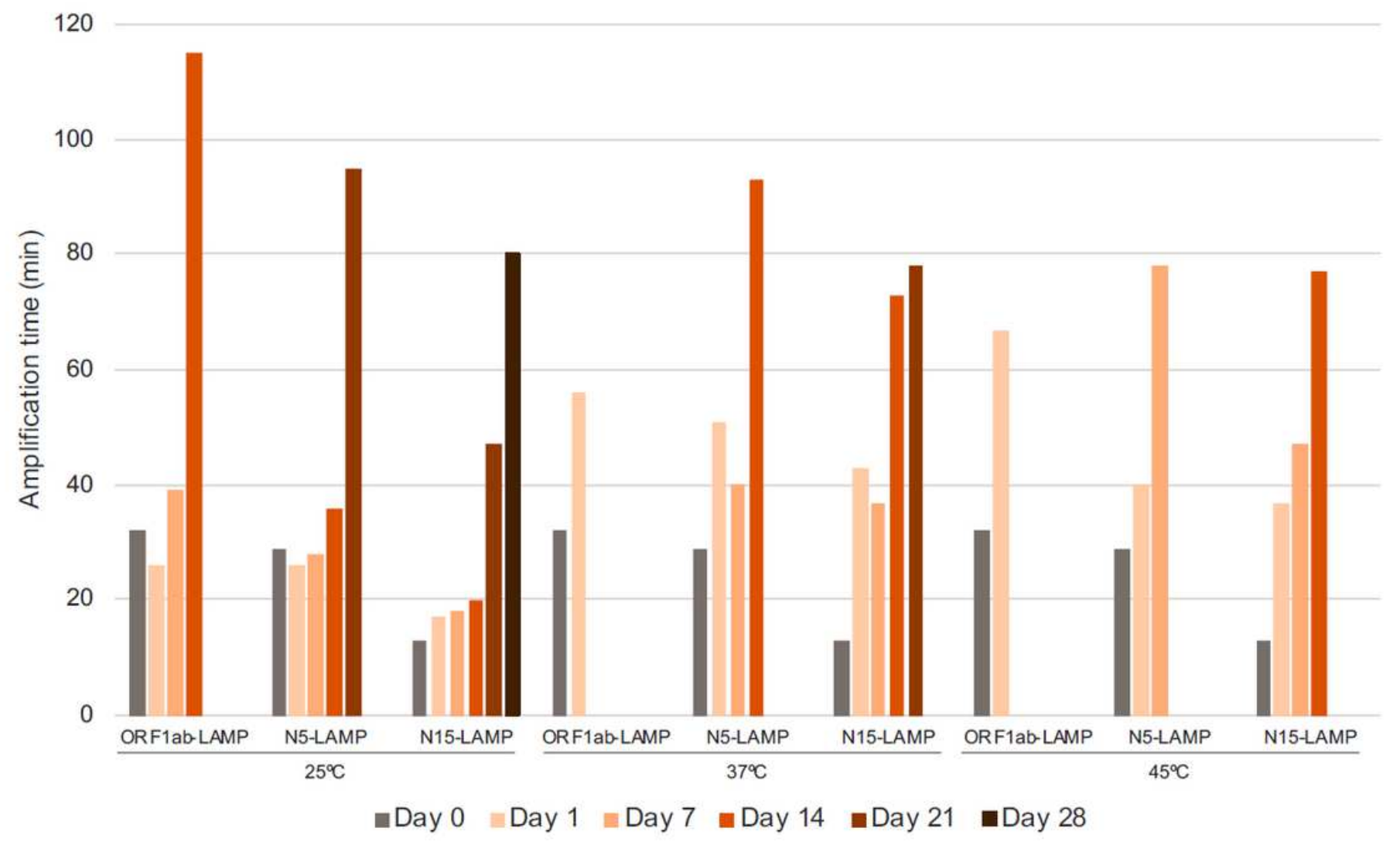

Figure 6

Amplification time of Dry-RT-LAMP assays as a function of storage time and temperature. Amplification times of C+ in RT-LAMP assays performed with dryreagents including primer sets ORF1ab, N5 and N15 tested at $0,1,7,14,21$ and 28 -days post-desiccation is shown. The different storage temperature $\left(25^{\circ} \mathrm{C}\right.$, $37^{\circ} \mathrm{C}$ and $45^{\circ} \mathrm{C}$ ) is also indicated. 


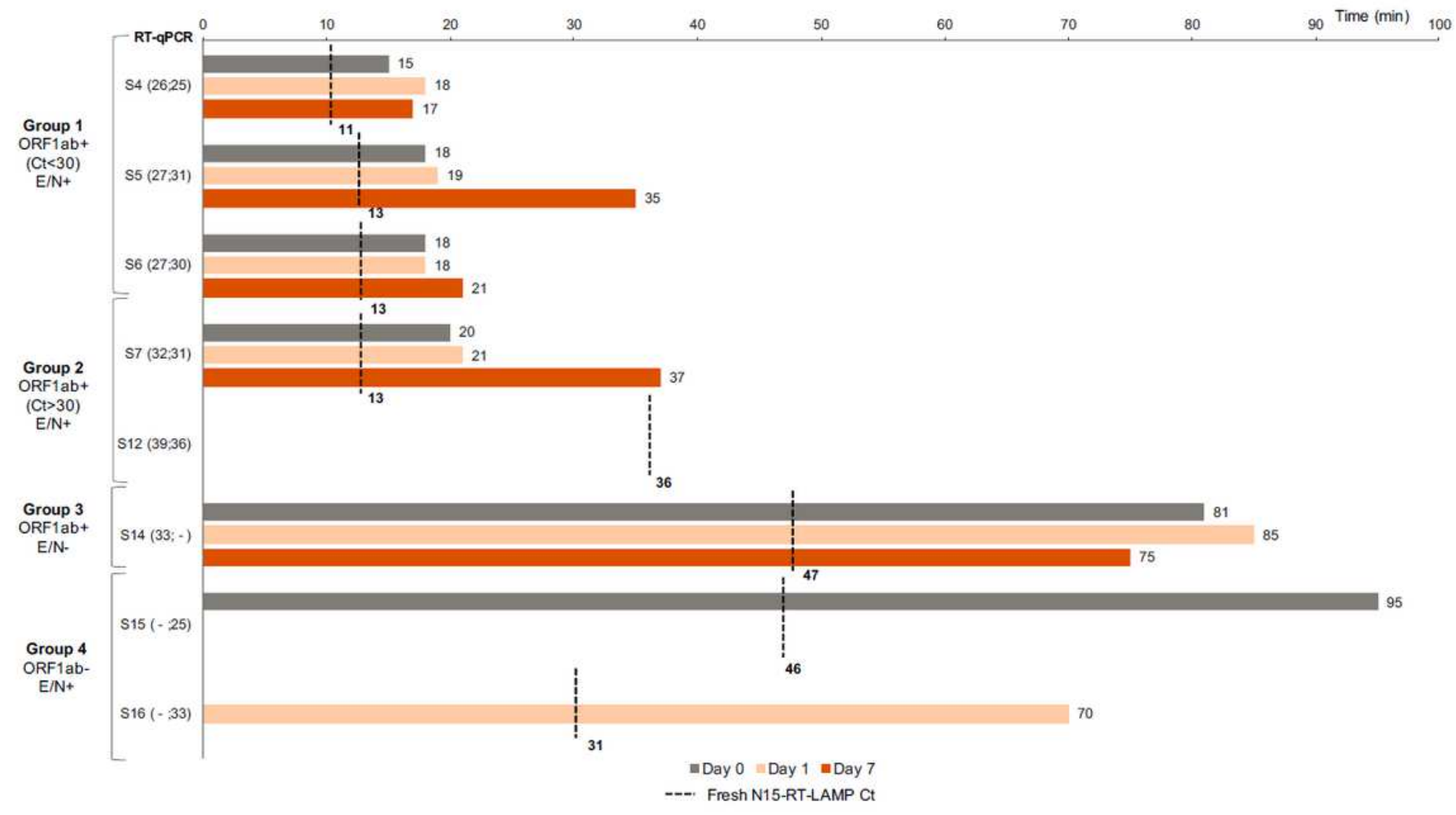

\section{Figure 7}

Dry-RT-LAMP assessment using primers set N15 in RNA isolates from COVID-19 patients. Amplification times of samples nos. $4,5,6,7,12,14,15$ and 16 , performed with dry reagents including primer set N15 at 0,1 , and 7-days post-desiccation are shown. As reference for comparison, discontinuous black lines indicate amplification times obtained in N15-RT-LAMP assays using fresh liquid mixes. 